Portland State University

PDXScholar

Spring 11-27-2013

\title{
Skateboarding as Transportation: Findings from an Exploratory Study
}

Tessa Walker

Portland State University

Follow this and additional works at: https://pdxscholar.library.pdx.edu/open_access_etds

Part of the Sports Studies Commons, Urban, Community and Regional Planning Commons, and the Urban Studies and Planning Commons

Let us know how access to this document benefits you.

\section{Recommended Citation}

Walker, Tessa, "Skateboarding as Transportation: Findings from an Exploratory Study" (2013).

Dissertations and Theses. Paper 1505.

https://doi.org/10.15760/etd.1515

This Thesis is brought to you for free and open access. It has been accepted for inclusion in Dissertations and Theses by an authorized administrator of PDXScholar. Please contact us if we can make this document more accessible: pdxscholar@pdx.edu. 
Skateboarding as Transportation: Findings from an Exploratory Study

by

Tessa Walker

A thesis submitted in partial fulfillment of the requirements for the degree of

Master of Urban Studies

Thesis Committee:

Jennifer Dill, Chair

David Morgan

Kelly Clifton

Portland State University

2013 
(C) 2013 Tessa Walker 


\begin{abstract}
In recent decades skateboarding has expanded from recreation into a form of transportation. Skateboarders appear to use roadways much as other nonmotorized modes do. However, there is little academic research on the needs and characteristics of the skateboard as a mode. This research reports demographics, multi-modal and travel behavior findings, and other data from an exploratory mixed-methods study of skateboarding as a mode of transportation.
\end{abstract}


For the skaters who showed me the familiar city as a new and different landscape. 


\section{Acknowledgements}

At Portland State I would like to thank my thesis committee members Jennifer Dill, David Morgan, and Kelly Clifton for their direction and advice. Also Emily Ford and Meredith Farkas in the library, Paula Carder, Charles Heying, Carl Abbott, and Jason Newsome for their stellar teaching, Carol Gabrielli and Dana Lundell in University Studies who manage to blend life smarts and work smarts so completely every day, and Cody Rich for his skating knowhow and most excellent ties. And to Janice Kettler and Kerri Opdyke for helping me stay on course - I am deeply grateful

A profound and happy thank you goes to my bike-tastic friends on the Family Activity Study for sharing many adventures in data collection, and to Quatama Mamas \& Dude Consulting for giving me wonderfully unrealistic expectations of my future coworkers.

I also want to thank my friends and teachers at Marlboro College, who demonstrated to me what truly excellent education is - I continue to be honored in considering myself as your student. A special thanks to Carol Hendrickson for the encouragement to finish this degree. Thanks also to the folks who encouraged me when I first dipped my toes into the planning and research professions, for assuming I would do great things and making it very hard to

contradict them - Jim Mullen and Sarah Brennan in Vermont, and Chet Douglass, Ilona Ferraro, Taru Kinnunen, and Thanos Zavras at Harvard.

To my parental units, whose kindly expectations and support me never wavered - Jerry Walker, David Stewart, and my dear mum Stephanie Judy. 
And to my friends. You let me live fully in my ramblings, grumblings, and geekery - I wouldn't be me without you. Aidan Sammis and Jamie Young, Sue McClintock, Ashley Bies, Michelle Wruck, Allison Turner, Josh and Louisa Engle, Chris Black, Aria Stewart, Vanessa Filkins, e* my starboi, Marina and Zack (and Rosabee), Ruth Stewart, Mitchell and Jamie Grey, Tony Bourke, Amanda Cort, Lauren Mitchell, Rachel Phillips, Alexis Grant, and Lillian Karabaic. And to my dancing and climbing buddies who helped me live in my body as well as my mind. 


\section{Table of Contents}

Abstract ... i

Dedication .... ii

Acknowledgements ... iii

List of Tables ... vii

List of Figures . . . viii

Introduction and History ... 1

Introduction ... 1

History ... 1

The Emerging Need for Skateboarding Research . . . 3

Literature Review ...5

Research by Field ... 5

Theorists' Framings of Skateboarders . . 7

The Skater as 'Other' ... 9

Co-Occurring Uses and Chaotic Public Space . . . 11

Skating as an Act of Spatial Reinterpretation . . . 15

Skating as Class-based Transgression . . . 16

Literature Review Conclusion ... 18

Research Aims and Study Design ... 19

Study Design . . . 19

Population and Recruitment . . . 20

Methods of Analysis . . 24

Quantitative Analysis . . 24

Qualitative Analysis . . 24

Methodological Limitations . . 26

Study Findings . . . 27

Demographic findings . . 27

Age . . . 29

Race and Ethnicity . . 30

Gender . . . 30

Education and Employment . . . 31

Living Situation . . . 31

Financial Status . . 32

Advantages of Skateboarding . . . 34

Disadvantages of Skateboarding . . 39 
Built Environment Advantages and Barriers . . . 42

Transportation Characteristics of Skateboarding . . . 44

Overlap of Transportation and Recreation Uses . . . 46

Mode Uses and Multi-Modal Data . . . 51

Route Choice ... 55

Safety - Perceptions and Practices ... 57

Safety - Danger and Injury ... 59

Regulatory Policy and Enforcement ... 61

Land Use Policy . . . 64

Skateboarders as Citizens . . 65

Mental Health Benefits of Skating . . 67

Skating as a Multi-Generational Subculture . . 68

Skaters' Understanding of Active Transportation . . . 70

Conclusions ... 72

Future Research Needs . . . 72

Conclusion . . . 74

Bibliography ...75

Appendix A: Glossary of Terms . . . 81

Appendix B: Key Stakeholders Contacted for Survey Recruitment . . 86

Appendix C: Qualitative Code Book ... 88

Appendix D: Human Subjects Approval . . . 89

Appendix E: Recruitment Flier ... 91

Appendix F: Focus Group Interview Guide . . 92

Appendix G: Survey Questionnaire ... 95 


\section{List of Tables}

1. Types of Skating Research by Field . . . 5

2. Skating Topics with Disciplinary Overlaps . . 6

3. Zip Codes and Postal Codes ... 22

4. Demographics I . . 27

5. Demographics II . . . 28

6. Financial Status . . 32

7. Ordered Responses - Reasons to Skate . . 35

8. Comparisons to Reasons for Riding . . 35

9. Social Skating . . 37

10. Best Seasons for Skating . . 40

11. Advantages and Barriers . . .43

12. Skateboard Types ... 44

13. Skateboarding Compared to Other Active Modes . . 45

14. Overlap of Types of Skating . . 48

15. Types of Skating by Age/Number of Years Skating . . 49

16. Mode Use Frequencies . . 52

17. Safety Equipment Rates of Use . . 60 


\section{List of Figures}

1. Recruitment diagram ...21

2. International website views . . 22

3. Mapped Respondent locations . . . 23

4. Excerpts on Age ... 29

5. Excerpt on Gender ... 30

6. Excerpts on Advantages ... 36

7. Excerpts on Convenience ... 37

8. Excerpts on Sustainability ... 38

9. Excerpts on Surface Conditions ... 39

10. Excerpts on Social Bias ... 41

11. Excerpts on A Place for Skaters ... 41

12. Excerpts on Tricks in Travel ... 45

13. Tricks and Transportation - Age Started . . 50

14. Excerpts on Life Stage ... 50

15. Excerpts on Skating and Other Modes ... 52

16. Excerpts on Three Multi-Modal Types ... 53

17. Excerpt on Grade ... 55

18. Excerpt on Finding Skate Spots ... 56

19. Excerpt on Bike Boulevards ... 56

20. Excerpt on Experience ... 57

21. Excerpt on Signals ... 58

22. Excerpt on Safe Stopping ... 59

23. Excerpt on Legality ... 61

24. Excerpts on Policy and Compliance ... 62

25. Excerpts on Skate Park Siting

26. Excerpt on Skaters as Neighbors ... 66

27. Excerpts on Skating and Mental Health . . 67

28. Excerpts on Skating with Family ... 69

29. Excerpts on Skaters in Civic Roles . . 69

30. Excerpt on Active Transportation ... 71 


\section{Introduction and History}

\section{Introduction}

In recent decades skateboarding has moved from driveways and skateparks to city parks and streets. It has expanded from recreation into a form of transportation. Skateboarding has been studied by researchers in urban design, geography, gender studies, sports behavior, trauma medicine, and cultural ethnography, but the use of skateboarding as a form of transportation has been the subject of little academic attention; no research directly focused on this practice has yet been published in the transportation research literature. ${ }^{1}$

Academic literature on skateboarding has typically focused on research exploring public space conflicts, skating as a recreational use, and skate culture's role in adolescent identity formation.

\section{History}

In the family of board sports skateboarding was the first major departure from surfing. In the 1960s surfers used roller-skate hardware and short pieces of lumber to create rolling boards for coasting the smooth new streetscapes of Southern California and riding the slopes of dry swimming pools and drainage canals (Borden 2001). The introduction of 'kicktail' boards with turned-up ends in 1969 allowed riders to lever their boards into the air and skateboard tricks began to gain popularity (Stevenson). The transition from clay wheels to solid rubber in the mid-1970s made skateboards more comfortable to ride (Hunter 143). The basic concept of the boards has remained the same since those initial innovations, but technological developments in skate hardware have branched out into many sophisticated types of board designs. The term 'skateboard' is by

\footnotetext{
${ }^{1}$ One journal article examining skateboard policy in California is current in press (Fang).
} 
now an umbrella term covering boards used for a range of subtypes of tricks, for skating on streets, long-distance skating, and downhill skating. The short boards we typically think of as skateboards have kicktails at each end designed according to the original 1969 patent - as "inclined lever[s] that is sloped upwardly and rearwardly ... In order to practice otherwise difficult spinning or pivoting maneuvers such as wheelies with much improved balance and safety [one] presses his rear foot upon and depresses the lever to tilt the skateboard upward" (Stevenson 1).

Through the '70s and '80s the focus of skating was predominantly on "street skating" which was comprised of tricks that utilized street furniture or the built environment, vertical tricks or "vert" performed on half-pipes or ramps and often featuring aerial maneuvers, and transitional or "tranny" skating which utilized the undulating hardscapes now commonly seen at skateparks. ${ }^{2}$ The rising subcultures of professional skating, skate-punk music, graphic design iconography, and clothing styles associated with skating sprang up as the discipline spread. In the 1980s and 1990s with the emergence of skating in televised extreme sporting events such as the X-Games the sport became more mainstream. Its social, visual, and recreation presence played out through professional competition circuits, product lines from surfing companies and newly formed skateboard brands, and skating figureheads like Tony Hawk and Rodney Mullen (Borden 155, Mullen). The expansion of board sports with the rising popularity of snowboarding around the same time helped normalize skating as no longer the 'new kid' in alternative sports (The Beginning of Snowboarding). Skaters began to take advantage of the adaptability of skateboards across a range of built environments, adopting the linear travel lines

\footnotetext{
2 Throughout this work "street skating" will refer to tricks that utilize street furniture, while "skating for transportation" will connote travel to a destination.
} 
of snowboarding to downhill skateboarding, which uses longboards and the momentum of gravity for long continuous runs. These boards gained popularity through the 2000s - longboards (some reminiscent of their surf board predecessors) have longer decks and wheelbase and softer wheels than conventional skateboards. They offer a smoother and more stable ride than smaller trick skateboards, and the kicktails which allow skateboards to leave the ground are either small relative to the board size or left off completely. Longboards are typically used for down-hill skating and for "cruising", or longer journeys which emphasize travel rather than tricks (for an extended glossary of terminology see Appendix I).

\section{The Emerging Need for Skateboarding Research}

Skateboarders as a group are proving themselves to be effective advocates for policy change at the municipal level through political dialogue, insurgent action on issues of street use and skatepark siting and construction, and as documentary filmmakers with a strong tradition of filming their interactions with the city. Some skaters are already self-identifying their riding as active transportation. In 2010 the Canadian national magazine MacLean's quoted a 25 year old engineer who was petitioning the city of Saskatoon, Saskatchewan "to allow longboarding as a green mode of transportation", and a 38-year-old in Peterborough, Ontario protesting against the city's ordinance which "sends a messages that alternative forms of vehicles are not acceptable" (Dehaas). In a 2010 Oregonian article Portland longboarders also stressed the utilitarian benefits of skating (Bachman).

In Portland the ordinance regulating skaters as street users came about through collaborations between skating advocates and the municipality (Dougherty; Learn). Other cities including Portland Maine and Minneapolis 
Minnesota have also legalized skating recently with an eye towards transportation (Orstendorff and Burgess, Municode). Mainstream media has framed skating as transportation occasionally as well, moving away from an existing dual narrative of skaters as adolescent misfits and daredevil athletes to portray skating as play, healthy exercise, or an alternative mode for commuting. Since the media and organizations with planning authority are already responding to this group of users it is appropriate for transportation researchers to join the conversation.

The purpose of this research is to gather initial information on skateboarding as a mode of transportation, to map out the general shape of this sub-field, and to identify topics for further research for use by transportation researchers, policy-makers, planners, and activists. Through electronic surveys and focus groups of skateboarders this research gathered information directly from individuals who use skating as a mode of transportation, exploring their perspectives and recording the experiences they have had using skateboards to travel in the urban street system. 


\section{Literature Review}

\section{Research by Field}

People who skate do so for a variety of reasons. Skating can be any combination of exercise, competition, skill building, socialization, protest, performance, or transportation. Researchers who study skating also do so for a variety of reasons. Research to date on skateboarding has been undertaken by several fields (see table 1), and common topics often span several disciplines (see table 2). These tables outline the occurrences of skating as identified through literature searches, and the following literature

\begin{tabular}{|c|c|c|c|}
\hline \multicolumn{5}{|c|}{ Table 1: Types of Skating Research by Field } \\
\hline $\begin{array}{c}\text { Skating Types as Addressed by } \\
\text { Academic Fields }\end{array}$ & Street Travel & Parks \& Plazas & Skate Parks \\
\hline Urban design \& landscape architecture & & $\checkmark$ & $\checkmark$ \\
\hline Epidemiological and injury reports & $\checkmark$ & $\checkmark$ & $\checkmark$ \\
\hline Transportation & & & \\
\hline Urban planning and land use & & & $\checkmark$ \\
\hline Urban policy and governance & & $\checkmark$ & $\checkmark$ \\
\hline Engineering of new skateboards & $\checkmark$ & & $\checkmark$ \\
\hline Ethnography and anthropology & & $\checkmark$ & $\checkmark$ \\
\hline
\end{tabular}

review explores pieces which treat skating as transportation or which otherwise inform this survey research. The works in the literature review are grouped thematically by common ways in which researchers utilize skating.

There are some areas of the literature on skateboarding which will not be included in the following literature review or otherwise integrating into this research. First, skateboard design physics or engineering thought experiments. The simple design and movement mechanics and design of skateboards has made them an recurring subject of hypothetical design experiments. With the 
exception of proposals written by skaters which integrate riding experience and behavior into skateboard design this

\begin{tabular}{|c|c|c|}
\hline \multicolumn{3}{|c|}{ Table 2: Skating Topics with Disciplinary Overlaps } \\
\hline By Topic & Content & Disciplines \\
\hline $\begin{array}{l}\text { Contested urban } \\
\text { space }\end{array}$ & $\begin{array}{l}\text { Focused on skating in plazas, public parks, and } \\
\text { interactions between skaters and authorities. }\end{array}$ & $\begin{array}{l}\text { Urban design } \\
\text { Architecture } \\
\text { Sociology } \\
\text { Anthropology } \\
\text { Public Policy }\end{array}$ \\
\hline $\begin{array}{l}\text { Subcultural } \\
\text { dynamics }\end{array}$ & $\begin{array}{l}\text { Includes alternative masculine identity formation } \\
\text { through skating, public play, branding and iconography, } \\
\text { and women in skating. }\end{array}$ & $\begin{array}{l}\text { Ethnography } \\
\text { Anthropology } \\
\text { Criminology }\end{array}$ \\
\hline $\begin{array}{l}\text { Epidemiology of } \\
\text { skateboarding } \\
\text { injuries }\end{array}$ & $\begin{array}{l}\text { Reviews of trauma cases and data sets on skateboarding } \\
\text { injuries, performed by medical researchers }\end{array}$ & $\begin{array}{l}\text { Epidemiology } \\
\text { Trauma medicine }\end{array}$ \\
\hline $\begin{array}{l}\text { Physics and } \\
\text { Engineering of } \\
\text { Skateboards } \\
\end{array}$ & $\begin{array}{l}\text { Because of their simplicity skateboards are used as } \\
\text { examples of design form, acceleration, and the physics of } \\
\text { movement. }\end{array}$ & $\begin{array}{l}\text { Engineering } \\
\text { Physics }\end{array}$ \\
\hline Design of skateboards & $\begin{array}{l}\text { Again because of their simplicity, industrial designers, } \\
\text { engineers, and others have offered modifications on the } \\
\text { skateboard structure. These are slightly instructive due to } \\
\text { the travel-oriented uses many authors assume for their } \\
\text { designs, but as most are theoretical practices which do } \\
\text { not impact current first-hand skating behaviors or } \\
\text { experiences. }\end{array}$ & $\begin{array}{l}\text { Engineering } \\
\text { Industrial design } \\
\text { Product design }\end{array}$ \\
\hline $\begin{array}{l}\text { Skate parks and } \\
\text { recreation }\end{array}$ & $\begin{array}{l}\text { Research on skating as a sport or recreation practice is } \\
\text { oriented towards the skatepark rather than the street, } \\
\text { with a focus on tricks, skater culture, and professional } \\
\text { skating. }\end{array}$ & $\begin{array}{l}\text { Urban studies } \\
\text { Sociology of sports } \\
\text { Landscape } \\
\text { architecture }\end{array}$ \\
\hline $\begin{array}{l}\text { Skate parks and land } \\
\text { use }\end{array}$ & $\begin{array}{l}\text { Some work has been done on the location of skate parks } \\
\text { as a political, social, and land use decision. Since } \\
\text { centralized locations sometimes perpetuate unwanted } \\
\text { issues and moving skaters reinforces their "nuisance" } \\
\text { status this is often viewed through a policy lens. }\end{array}$ & $\begin{array}{l}\text { Urban studies } \\
\text { Public policy } \\
\text { Urban planning } \\
\text { Sociology } \\
\text { Public Policy }\end{array}$ \\
\hline
\end{tabular}

topic will be bypassed. Some issues of landscape architecture in skatepark design and siting are addressed occasionally in the land use planning literature, and will only be covered later in relation to themes emerging from the study findings since they generally fall under recreational use rather than transportation. Content produced by skaters for the skate subculture was not used in this 
research, in the interest of keeping an academic focus and our of recognition of the existing anthropological work on skating. Finally, this research will approach skateboarding as a valid means of transportation. While some design and planning approaches seek to 'design out' skateboarding as a use, I feel that the time has come for research which integrates skating with other travel modes. A range of external pressures support this position; the rising financial and environmental burdens of fuel, the increased value placed on active transportation by both the public health and planning sectors, and the fact that skating are already being utilized for transportation all justify transportationfocused research on skateboarding.

\section{Theorists' Framings of Skateboarders}

Urban theorists working mostly in the realms of public policy and urban studies have utilized the act of skateboarding as a mechanism for examining other issues. The existing academic literature on skateboarding consists mainly of case studies on contested urban space in public parks and plazas, summaries of qualitative research on the social subcultures, and medical reports which cover types of injuries in specific populations. In many of these studies skating is not actually the focus of the research queries, but instead acts as a site or population for exploring other hypotheses. Because this is a consistent feature of much of the existing literature, the following review will be organized thematically based on how researchers are utilizing skateboarding as an aspect of their overall research aims.

Skaters are framed several ways by urban theorists. This is in part determined by the theoretical framework in which skating is presented, in part by the broad spectrum along which researchers can be categorized in terms of the degree to which they politicize the practice of skating, and in part by how 
assumptions about skating are enacted by the researchers during data collection and analysis. Ethnographic and anthropological research tends to frame skating as subcultural performance, social play, or alternative masculine identity building (Beal; Borden; Karsten and Pel; Pomerantz et al.; Steyn). It tends to be relatively un-politicized, and conclusions about skating are drawn from the research rather than being presupposed. Urban designers and other urban studies theorists tend to use 'right to the city' issues around the politicization of use of public space, as well as the political and land use decisions associated with where to successfully locate skaters (Borden; Lefebvre, Németh; Nolan; Stratford). There is often a strong political aspect to these studies - typically political or civic interactions are the core of the research where skaters are used as examples of these interactions (Németh; Rogers and Coaffee; Lees; Woolley). The degree to which researchers make assumptions about skaters' actions varies from study to study. Sociologists tend to see the same political conflicts as urban theorists and combine them with explorations of the social role of skaters within society. These papers encompass a broad spectrum of politicization and assumptions. All of these groups often imply that something must be 'done with' skaters. Much of the existing research subscribes to a common premise that the presence of skaters in the social systems of public space is anomalous and outside the accepted uses for the space. The framing of skating as an anomalous social performance is due to several aspects of how skating is viewed. These include the skater as 'other'; co-occurring uses and chaotic public space; skating as act of spatial reinterpretation or transformation; and skating as class-based transgression. These four categories are examined below.

Skateboarders are sometimes utilized as a proxy for other youth populations, or as an example case for analyzing the actions of municipalities (Nemeth; Nolan; Stratford). The logic of these study designs is evident - skating 
practice is visible, the population generally isn't risky to work with compared to populations involved in gang or drug activity, and the presence of skaters can be civically or socially divisive. However, I feel that researchers should be careful in utilizing skaters for examining other topics without a clear understanding of the values, needs, and practices which comprise skateboarding culture.

\section{The Skater as 'Other'}

The various subcultures which have developed around skateboarding tend to place an emphasis on independence from the mainstream; both participant and outsider views on skating subculture assign it a social status of 'other' in categories including gender, class, and legality of behavior. Ethnographic researcher Becky Beal described in her research on masculinity in skate culture that male skater's self-perceptions of identity tend to center on "alternative masculinities" that rejects 'jock' stereotypes in favor of punk, straight-edge, or other social identities (Beal 3). In interviews with 41 Colorado skaters Beal found that street skating - as practiced by adolescents and amateurs - was highly cooperative and was more akin to perfecting works of performance art than to competitive sports. Skaters considered themselves "more reflective than their average peers", and their descriptions made skating seem more like an art than a sport, stressing the freedom of self-expression, the collaborative nature of perfecting tricks, and a preference for collective practice over competition (Beal 4). Beals also found that social dynamics rather than civic conflicts were the main focus for most skaters. She observed the formation of a collective skater identity built through the process of social engagement with other skaters.

While Beals' work suggests that some skaters choose to skate as a way to set themselves apart from mainstream sports (especially team sports), some aspects of the skateboarding subculture conform neatly to the construction of 
male sport sociology. Despite the individualist, non-competitive nature of skateboarding, skating still fits well with several of the criteria of sports culture as defined by Don Sabo in his work on masculine identity and social structure in the culture of football. These include participation in rituals, initiation through pain, and an environment segregated from participants' families and from the opposite sex (Sabo and Panepinto 120). The recreational context where many people learn to skate meets these criteria via regular skate spots, routine minor injuries, and peer groups with high levels of homogeneity. This suggests that skating is more normalized than it appears, likely running in parallel with the identity development associated with more mainstream sports while still maintaining a distinct value system which allows participants to develop a subcultural group and individual identity.

The sports-like dynamics of skating create a second layer of 'otherness' which is important to note (though this research did not make it a special focus): the marginalization of women in skateboarding. Some of the same values of noncompetitiveness and skills-mentoring that differentiate skating from other maledominated sport forms actually help to re-create "an ideology of male superiority and of patriarchal relations" within the subculture (Beal 6). Beal reports that female skaters tend to encounter barriers to entry that aren't necessarily intentional or perceived from the perspective of male skaters, leading many of her male interviewees to assume that women simply weren't interested in skating. ${ }^{3}$ Since Beal's publication in 1996 some of these dynamics may be changing, though the gender ratio still skews male.

\footnotetext{
${ }^{3}$ Some of Beal's female interviewees described choosing to emphasize the typically male traits within their personalities while skating in order to fit in with the subculture of the sport, a tactic that could lead to interesting research within womens' and gender studies on gender identity and performance in skating. While the majority of the current academic theory on female populations and skateboarding uses the second-wave feminism rhetoric of inequality and exclusion, a few authors are using skating as a lens through which to explore more progressive forms of feminist theory, seeking to keep feminism relevant to younger generations by exploring successes for women in skating, and using female skateboarders as an
} 
Outsiders' views of skating subculture vary, but there are a collection of negative assumptions about skaters which seem linked to the practice of young people spending time in public spaces. These negative perceptions conflate skating with drug use, gang activity, homelessness, or behavioral issues, thus framing skaters as an 'other' to be feared, thus legitimizing regulatory control of skating behaviors. These controls take the form of both enforcement policing and environmental design. Some guides for crime prevention through environmental design (CPTED) group skating in with other undesirable behaviors, with lists such as one from San Diego which prohibits conduct such as "trespassing, fighting, threatening others, panhandling, vandalism, skateboarding, littering, soliciting, loitering, illegal lodging, prowling, loud noise or music, consumption of alcoholic beverages, drug activities, etc." (San Diego Police Department 15; CPTED Vancouver). Some researchers hypothesize that the reason for the negative reactions to skating is the rarity with which groups make extended use of public space; they propose that the occupation of public space by groups of young people is currently so rare that all non-consumer behaviors are a form of class transgression (Karsten and Pell 339; Lees 615). Others see skate spots as sites of social and political contestation originating in the overlapping uses of the space by various groups; these views will be explored below (Nolan; Németh; Rogers and Coaffee; Stratford).

\section{Co-Occurring Uses and Chaotic Public Space}

The actions of skaters are often examined within the spaces of public plazas, parks, or squares. These are sites with many co-occurring uses which overlap spatially, temporally, and socially, so the spatial needs of skateboarding in public plazas and parks tends to co-exist with uses from other groups. Prime

example of third-wave feminist theory in practice and as an example of subcultural resistance (Pomerantz et al, 550, Vivoni, 130). 
spots for street skating often utilize street furniture, hardscape installations, and access-ways such as stairs and ramps. Skate trick practice can be loud and repetitive, and the perception of danger is high since skateboards sometimes shoot off on unpredictable trajectories and minor injuries are common. Some of the best trick spots are originally designed to serve as seating, fountains, or other structures generally symbolic of serene or restful activities. Because of the energetic presence of skateboarding the dynamic of coexistence between skateboarding and other uses in public space can become fraught.

Researchers frame this a couple of ways. In his study of skaters in public space in Newcastle, Australia, Nolan describes skating as an act of spatial transgression and re-interpretation of established use-programs. He asserts that the presence of skaters: "highlights the way spaces are constructed and reproduced as normative landscapes, and how values and meanings are attached to these place" through challenging the accepted uses for public space (Nolan 311). He argues that skating explicitly reinterprets public spaces, and that the conflicts that sometimes arise as a result are not due to the presence of skateboarders but rather the dawning recognition by other social groups of the multiple meanings of the environment, as demonstrated through skaters' actions. Ethnographers Karsten and Pel discuss similar conflicts in their analysis of street skating practices in Amsterdam. Skaters they interviewed had value systems for their interactions with the built environment which were at odds with the preservation priorities of civic and political groups. According to Karsten and Pel the skateboarder they interviewed were often the most frequent users of the parks and plazas where they practiced, and their opinions were based in an a detailed social and structural knowledge of the spaces. Yet this knowledge did not translate into civic influence in the management of those spaces - rather, skaters voluntarily annexed themselves to other areas when conflicts arose. The 
authors described skaters as: "nomads of the city for whom there is little room. They find refuges such as the half pipe under the Schellingwouder Bridge, which is located at the edge of the city where no one else would want to go. Skaters are left alone there and have the freedom to do as they please." (Karsten and Pell 337). Karsten and Pell observed that skaters and other groups interpret public space differently and that skaters tended to relocate to avoid conflict, while Nolan concluded that conflicts between skaters and other groups occurred when public or social spaces ware reinterpreted without collective consent.

In Conflict, Exclusion, Relocation: Skateboarding and Public Space Jeremy Németh examines the skating ban at Philadelphia's Love Park - a long-time center of innovation and creativity on the national street skating scene, where skating was banned and anti-skate designs were implemented in 2002 (Németh 2006). Németh uses the Love Park case - and the act of skating - as one example of larger issues of exclusion, spatial politics, and prescriptive definitions of public space. This is an account of social and political currents, with skating used as an example case. The skater-produced Love Park Documentary and the 99\% Invisible podcast episode "In and Out of Love" describe the centrality of these events to the skating community (Love Park; Mars). Skaters write on Love Park as the site of key artistic and social developments in "the east coast's golden era [when] there's obviously more to [these skaters] than just Love Park" (Williams). And the park's designer emphasizes the importance of unforeseen collaborations between designed space and unanticipated users (Mars). It seems that the physical space of Love Park acted as a key site for overlapping interests, among them the street skating community and Philadelphia's regulatory agencies. By focusing on the policy and public space theory of this case Németh may in fact of de-emphasized the significance of the site to the very population he used as his example case. Stratford examines similar questions of the roles and rights of 
skaters in Franklin Park in the city of Hobart, Australia. Her arguments are rooted in theories of urban governance, civic participation, and rights to public space (Stratford). While she captures and characterizes skaters' point of view effectively, she is ultimately exploring questions which could be applied to many groups utilizing public space - here, skateboarders are an example population rather than the topic of study.

Rogers and Coaffee directly address an issue implied in the three previous articles in their examination of the exclusion of skateboarders in city centers in the United Kingdom. While classifying skating as recreation they pick up on an essence of freedom which seems key. They write that "antagonism to dominant orders is at the heart" of skating identity, and they pose the question of how best to develop "shared understandings of 'quality of life" between diverse groups of urban users" (Rogers and Coaffee 335).

These articles have excellent scholarship, but they make two assumptions about skaters: first, that skating is a form of recreation only; and second, these scholars defined public spaces as plazas and parks only, excluding the public right-of-way network of our streets. In these cases, studies of the conflicts which played out in physical space was more accurately a difference in beliefs or opinions about how common spaces should be used than explorations of the full range of activities performed by skaters. It could be that this distinction has stayed undefined since skating coexists as both a type of recreation and a form of transportation. In the case of Portland's skateboard policy (Ordinance 16.70.410 in its current iteration), the combination of skating as a utilitarian practice and the right to public space were clearly articulated early on. Commissioner (now Mayor) Charlie Hales set skating as transportation front and center in a 2001 Oregonian interview saying: "I get passionate about this issue because it's about giving people choices and sharing the streets. Any law-abiding citizen ought to 
have the right to move about the city by a choice of means. It became a much more complicated augment, about whether skaters are legitimate citizens ... We're giving people a choice in how they get around" (Learn). This interview touches on many of the 'right to the city' theories investigated in existing skateboard research, but also brings transportation uses to the table. Perhaps such integrated approaches to public space theory and utilitarian practice could show the way to more integrated analyses of recreation and transportation narratives once there is data of both behaviors to compare. Regardless of when skateboards became defined as transportation, skaters are an established presence on city streets.

\section{Skating as an Act of Spatial Reinterpretation}

Skateboarding uses the built environment in unanticipated ways. In street skating stair railings become slide rails, benches become jumps. Skating interacts with the built environment with the utmost physicality - a good skate trick has a phase of preparation followed by execution, a landing, and a constant visible fight between the rider and board, momentum, gravity, and the landscape. Because of this different approach to the built environment skating becomes a topic of contention among stakeholders with various value systems relating the built environment, and skating also becomes a topic of interest for researchers looking for new lenses through which to examine the built environment. Some of the policy-focused authors above explore these ideas in general (Nolan, Németh). Other authors make this the main focus of their research.

In her analysis of young adult skateboarders in city centers in the United Kingdom, Woolley concludes that skateboarders intentionally re-interpret urban places. Her study focused on skating in plazas and parks, and she offered a vision of the right to public space based on amounts of use rather than on 
financial interest (Woolley). Francisco Vivoni also assigns skateboarders agency for changing how space is understood and interpreted through their actions. He views the use of public plazas for skateboarding as an "avenue for practicing contestation" of the forms of control exercised in those spaces (Vivoni 131).

Both Wooley and Vivoni propose that skaters consciously act to reinterpret public space. It is tempting to push this interpretation further, framing the choice to perform skate tricks as a statement of social rebellion intended to directly impact both the built environment and the civic actors who are concerned with its quality. Both Vivoni and Wooley tend towards this conclusion in their work. However evidence of overt rebellion sourced from interviews is rarely focused on specific spaces or civic groups - the act of skating may be a generalized protest, a sort of social statement of the subculture's presence, but most current research does not suggest that skaters set out to explicitly demonstrate new use programs for spaces to stakeholders outside their own subculture.

\section{Skating as Class-based Transgression}

Skating often involves what is perceived as a lot of 'hanging out' by young people in public spaces. The lack of consumption behaviors or tangible normative social hierarchies in skating subculture appears to make skaters' socioeconomic standing somewhat illegible for researchers. This inability to read class into skateboarding subculture is based on several things. Steyn offered a clear argument for skaters' apparent classless status arguing that the subculture's visible style markers obscure many of the visual signals that convey class (Steyn 15). The street style clothing and iconography present in skater culture, assumptions of drug or gang activity, the public idleness which in is sometimes societally conflated with homelessness, the youth of skaters amassed in groups 
and of an age when many people act out. In fact, in many places the occupation of public space by groups of young people is currently so rare that the all nonconsumer behaviors will be assumed to be some sort of mischief (Karsten and Pell 339; Lees 615). Lees emphasizes the debate of use-based ownership versus economic ownership of space in her discussion of the presence of skateboarders in downtown Portland, Maine. Her debate is framed as a comparison between youth as consumers of night life versus the financially 'non-contributing' status of skateboarders. The piece explores the conflicts between the activities of youngsters and long-established residents in Portland, Maine - the author describes late night noise problems from bars and nightclubs as having "offended nearby residents", while the same paragraph characterizes skaters' daytime trick practice as a "combat zone" 4 (Lees 624). While it is easy to read this as a market-based analysis of the increased social acceptance of inconvenience that come with monetary returns, this is still a very stark comparison of the two types of use by roughly equivalent populations from (usually) roughly equivalent backgrounds.

According to researchers the conflation of skateboarding with issues such as homelessness or chronic drug use are mislead assumptions. Both Steyn and Karsten and Pell suggests that the make-up of skater subculture is not generally drawn from disadvantaged populations or groups that utilize the drug trade or occupation of public space because they lack access to alternatives. Research suggests that skater demographics consisting of predominantly of middle and upper-middle class youth, in groups which are "highly consistent across the socially constructed categories of age, class, race and gender" (Steyn 15).

Ultimately the mechanics of how skaters utilize the built environment does not seem to be consistently linked to other negative youth behaviors with

\footnotetext{
${ }^{4}$ This use of the "combat zone" here also refers to a neighborhood in Boston commonly called the Combat Zone, which was experiencing gang- and drug-related problem.
} 
which it is categorized. However, because the geographic locations favored by some skaters overlap with spaces used by other populations whose behaviors are viewed as problematic, they sometimes get grouped together from a social systems standpoint where "by-laws [or] banning orders ... in some cases, have lead to criminal prosecution" (Rogers and Coaffee 327). Skating tends to incur moral and literal policing along with homelessness, graffiti, and drug, crime, gang activity, and other issues with large youth populations which respond poorly to regulatory mechanisms (CPTED Vancouver). Current research on skating has only sometimes been able to parse the practice of skating from social assumptions about skaters. This makes it hard to find objective information on skating for academic evaluation purposes.

\section{Literature Review Conclusion}

Skating has been used by researchers in various disciplines as an example for examining civic, social, and spatial conflicts. Case study examples of skateboarders are available within the literature, but there is a lack of basic demographic data on the skating population, and most studies utilize skating as an example of other phenomena rather than positioning skaters' own experiences and opinions centrally in the data findings. The literature as it stands is thematically broad, but is as yet unconnected with questions of skateboarding as transportation. 


\section{Research Aims and Study Design}

\section{Study Design}

Skateboarding is already being utilized as a transportation mode on our streets. Currently there are no established data sets for evaluating the needs and travel behaviors of skaters. For this research a mixed-methods approach was selected in order to discover similarities between skating and other nonmotorized modes, and also to open an opportunity for skateboarders to share narrative explanations of their decisions and experiences, capturing nuances of skating which do not readily emerge through observation- or quantitative-only methodologies.

The aim of this research was to develop a general picture of skating for transportation as it is currently practiced and experienced in the U.S. and Canada. As an exploratory study the types and scope of the research questions were intentionally quite broad. The study framework was developed by referencing a range of sources:

- Questions used in bicycle transportation research were included in the research instruments in order to facilitate comparisons between the bike and skate modes and identify any potential similarities in route choice, multi-modal travel, or reasons for riding.

- A modified travel journal was included in the survey in order to collect trip data.

- Based on accounts of the social nature of skating in the ethnographic research literature, socialization was identified as a possible reason for skating and was tracked separately from transportation in the survey instrument where possible Based on current questions about the overlap 
between recreational and transportation cycling populations, skate parks and trick practice were tracked separately from transportation in the survey instrument where possible.

- Existing methodological papers and studies on non-motorized transportation were referenced as guidelines where available.

- Some non-transportation literatures which covered skating were also utilized. These sources are described and cited in the pertinent sections below.

- Due to the varying legal status of skating in the geographic study area, policy questions were approached from the perspective of skaters' knowledge of local laws and their experience with enforcement, rather than from the regulatory language itself.

Survey and focus group questions were designed to capture basic data on skaters' travel behaviors, reasons for skating, demographics, experiences with policy and law enforcement, and the advantages and disadvantages of skating as a form of transportation.

\section{Population and Recruitment}

Data for this study was collected using two research instruments. First an online survey was made available to skaters age 18 and older throughout the U.S. And Canada (see Appendix IV). This survey included demographic questions, modified travel journals, and travel metrics based on bicycle transportation research. It also captured qualitative data in the form of openended questions on the advantages and disadvantages of skating, and participants' skating experiences. 
The recruitment profile for this study was intentionally broad. The electronic survey was open to anyone age 18 or older in the U.S. or Canada who had skated for transportation within the last five years. A five year span was chosen in order to facilitate a larger sample size but recruit respondents who remembered their skating experiences accurately if they were no longer skating. Skaters under 18 were excluded due to potential Human Subjects issues regarding asking minors residing in locales with skateboard bans to disclose illegal behaviors. Findings from this study show that many respondents skated for transportation during adolescence (see Age, below). Future research might benefit by engaging younger population as a way to expand the study age impacts across the skating population and to document school commute trips.

The survey was distributed via snowball sampling, outreach to key stakeholder groups (see Appendix B, and Fig. 1 - recruitment

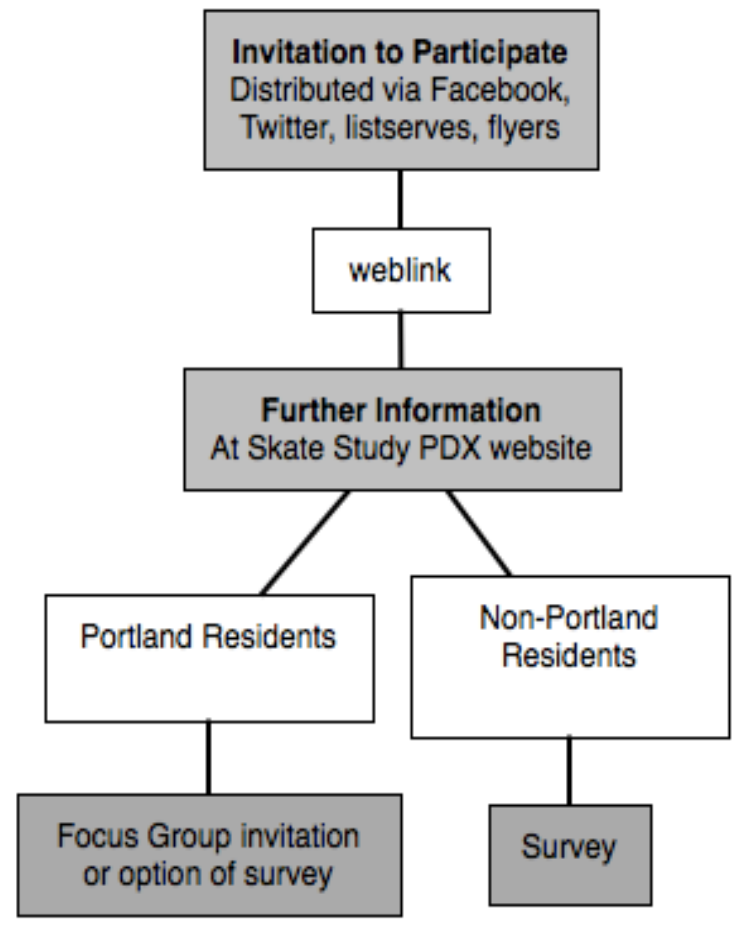

Figure 1:Recruitment Diagram diagram), and paper fliers at key sites in Portland. Fliers for the study were distributed on the Portland State campus as a recruitment tool for focus groups, by hand to friends and acquaintances in Portland, to skaters on the street, and to skate shops, community-based bike shops, and stores selling skating accessories in NE, NW, SE, and downtown Portland. Key stakeholder group and individuals 
who were contacted online were identified as central to skateboarding organizations in their region or within the field of active transportation research.

Electronic announcements about the survey drew 3,387 views to the study website over ten weeks. Facebook and Twitter links, the PDXdownhill and OTREC websites, and the Silverfish Longboarding forums were the top referrers. Eighty percent of views originated from the U.S., and 10\% came from Canada.

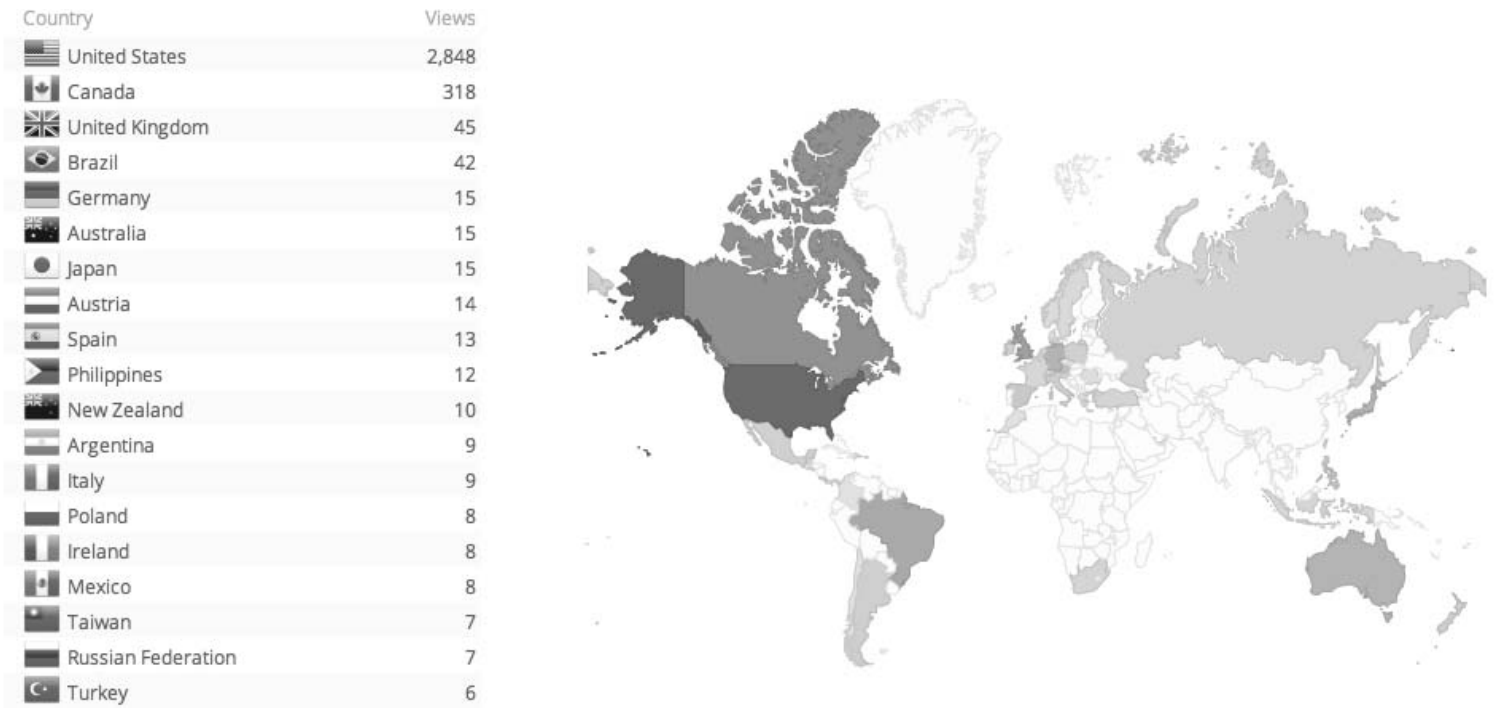

Figure 2: International Website Views

The study website had an unexpected international reach, with a combined $3 \%$ of views from the UK, Brazil, Australia, Germany, and Austria, and with visitors from 38 other countries comprising the final $7 \%$ of views. (see Fig. 2 of international website views, above). A handful of survey responses from overseas were identified.

Table 3: Zip Codes and Postal Codes

\begin{tabular}{|l|c|}
\hline Total $\mathbf{( n = 2 0 0 )}$ & $\mathbf{1 0 0} \%$ \\
\hline Canada & $18 \%$ \\
\hline United States & $82 \%$ \\
\hline Portland, OR & $30 \%$ \\
\hline
\end{tabular}

While they were not included in analysis their contents were reviewed and was found to be highly consistent with the responses form study participants in the U.S. and Canada. Skaters from across the U.S. and Canada responded to the survey - of the respondents who submitted location data, $82 \%$ were within the 
U.S. And 18\% were from Canada (see mapped respondent locations, p. 22). Thirty percent of the total were from the Portland Metropolitan Area (see table 3, Zip Codes and Postal Codes).

Three focus groups with a total of 14 participants were conducted in Portland, Oregon. These discussions covered topics similar to the survey but explored riders' experiences in greater depth and also included an exercise to capture route choice prioritizations. Focus groups were conducted after the majority of the survey responses had been collected. Initial coding on qualitative survey responses took place before focus groups, which informed a few new

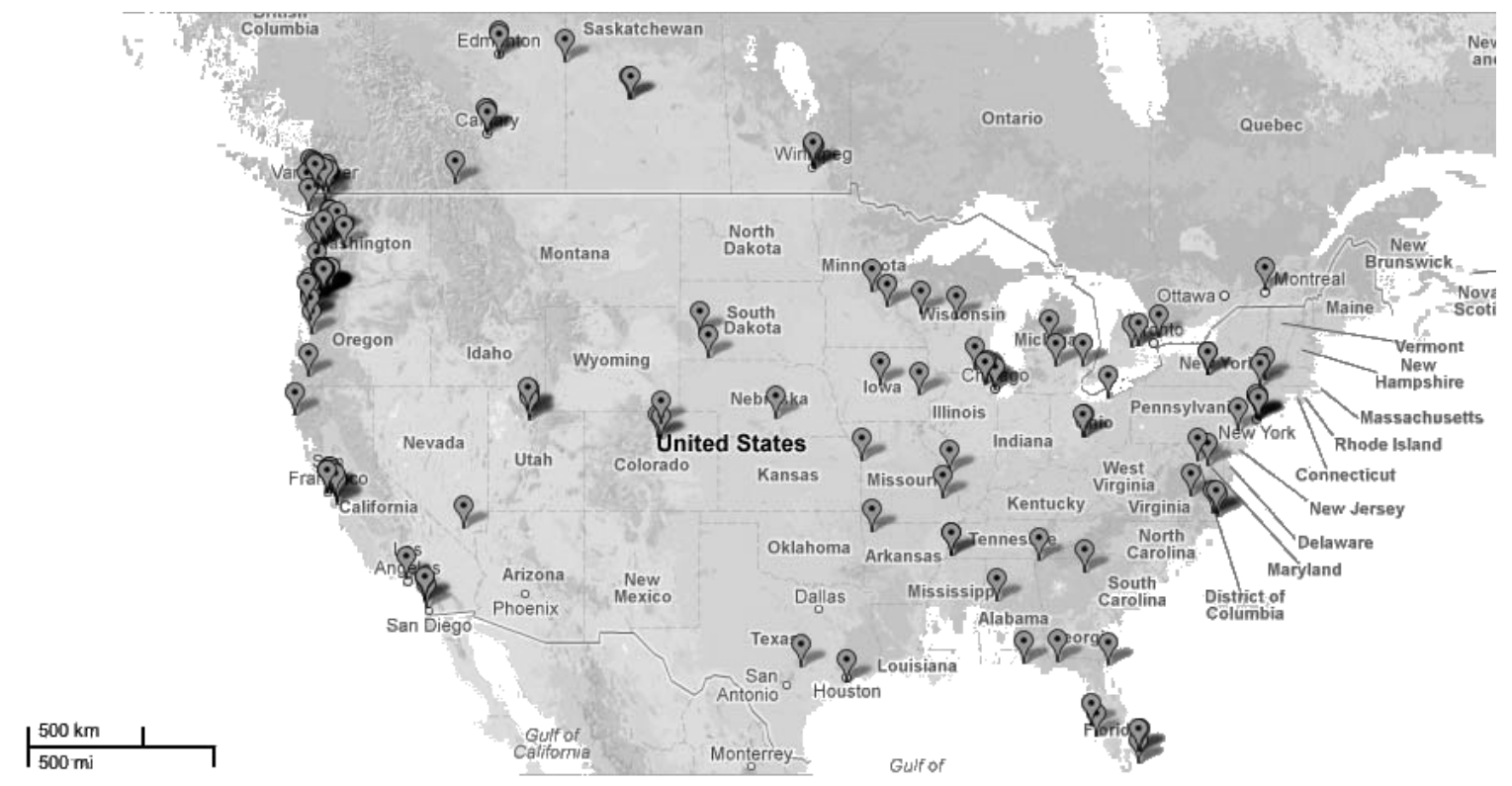

Figure 3: Mapped respondent locations

probes for the group discussions. For the purposes of demographics collection all focus group participants completed the demographics section of the survey instrument, (see demographic findings). 


\section{Methods of Analysis}

\section{Quantitative Analysis}

Quantitative data and demographics were analyzed using descriptive statistics. Travel journal data was collected (due to time constraints they have not yet been modeled). In order to encourage high response rates all survey questions were optional and many respondents skipped some questions. As a result, the response rate varies throughout the data set. For each question percentages will be calculated based on the total response rate for that question, and the number of respondents who did and did not respond will be noted by the total.

\section{Qualitative Analysis}

Qualitative data was analyzed using a Grounded Theory approach, utilizing Dedoose software (Glaser and Strauss). Categories and themes were allowed to emerge organically from the data, but were organized in some cases to align with standard topics explored within non-motorized transportation research. The data from the survey and focus groups were analyzed separately. On comparison the categories and themes from both data sets proved highly consistent, so findings from the two parts of the study were combined rather than being addressed separately. For themes where the breadth of survey data and the depth of focus group data do not form a cohesive narrative study respondents and focus group participants will occasionally be dealt with separately.

Since much of the survey data had been collected before focus groups convened, a portion of time in focus groups was allotted to clarifying responses 
from the surveys and exploring those topics in more depth. The divergent experiences within focus groups were most frequently due to different riding styles or to varying views of the role of skaters in the larger culture; focus group participants formed consensus around the majority of topics. The focus group data did generate some coding categories not present in the survey data due to the less structured format of the method (see Appendix $V$ for codes).

The process of analysis through coding (see appendix IV: qualitative code book), generated categories which were then grouped thematically. These themes (listed in fig. 4, right) were developed mainly as groupings suggested by the data, but also with an eye to the categories typically explored within active and/or non-motorized transportation research.

The coding and categorization of qualitative findings showed consistent themes emerging across the range of participants, as well as when survey and focus group research were compared (for a complete list of codes see Appendix III). This suggests that the focus groups achieved data saturation and that the resulting information is - from a skaters perspective - pertinent and reasonably complete within the scope of the study goals. It also indicates skaters' attitudes and experiences may be able to be generalized geographically. While some questions of paving quality or local regulations have local causal origins, more general needs and opinions where shared by local skaters and those who responded to the survey from across the U.S. and Canada.

Qualitative analysis for this project focused on the points of view and personal experiences of skaters. The conflicts and concerns - as well as the specific benefits - of skating were brought up by skaters themselves, and reflected their own interpretations and experiences. 


\section{Methodological Limitations}

While study recruitment exceeded the original goals of the study design by over $350 \%$, the study population for this research was still small, and may not be representative of the general skating population in all cases - further study is needed in order to fully understand the travel behaviors of skateboarders, and to begin to identify differences in the population due to locale, gender, age, experience, and other factors.

Because study recruitment focused on individuals who skated for transportation, data on other types of types of skating and types of skateboards used may not be representative of the skating population in general. Because survey recruitment was conducted primarily online it is possible that individuals with limited computer access were under-sampled; this may have skewed demographic data related to socio-economic status, such as educational attainment and financial status. This research also does not accurately reflect the entire age range of the skating population, since it was limited to those age 18 or older. It is likely that there is information about skating as transportation, as community, and other experiences which would emerge from research which included younger skates.

As exploratory research the outcomes of this study provide only an initial step in our understanding of skateboarding as transportation. 


\section{Study Findings}

\section{Demographic Findings}

Demographic results from the survey (see tables 4 and 5) showed that survey respondents were $90 \%$ male, $82 \%$ white, and $67 \%$ had attended or graduated from college. Thirty-four percent worked full-time and 31\% were in

\begin{tabular}{|c|c|c|}
\hline Table 4: Demographics I & $n$ & Percent \\
\hline \multicolumn{3}{|l|}{ Age } \\
\hline $18-20$ & 42 & $20 \%$ \\
\hline $21-25$ & 63 & $30 \%$ \\
\hline $26-30$ & 40 & $19 \%$ \\
\hline $31-35$ & 18 & $8 \%$ \\
\hline $36-40$ & 20 & $9 \%$ \\
\hline $41-45$ & 18 & $8 \%$ \\
\hline $46-50$ & 8 & $4 \%$ \\
\hline $51-55$ & 3 & $1 \%$ \\
\hline Total & 212 & $100 \%$ \\
\hline Did not respond & 252 & \\
\hline \multicolumn{3}{|l|}{ Race } \\
\hline Caucasian & 204 & $82 \%$ \\
\hline American Indian / Canadian First Nations & 9 & $4 \%$ \\
\hline Other & 8 & $3 \%$ \\
\hline Hispanic & 7 & $3 \%$ \\
\hline Asian & 6 & $2 \%$ \\
\hline Latino & 5 & $2 \%$ \\
\hline Indian Subcontinent & 3 & $1 \%$ \\
\hline Middle Eastern / Arab & 3 & $1 \%$ \\
\hline Native Hawaiian Pacific Islander & 3 & $1 \%$ \\
\hline African American / Black & 1 & $<1 \%$ \\
\hline Total & 249 & $100 \%$ \\
\hline Did not respond & 215 & \\
\hline \multicolumn{3}{|l|}{ Gender $(n=231)$} \\
\hline Male & 208 & $90 \%$ \\
\hline Female & 19 & $8 \%$ \\
\hline Non-binary gender identity & 4 & $2 \%$ \\
\hline Total & 231 & $100 \%$ \\
\hline Did not respond & 233 & \\
\hline
\end{tabular}


Table 5: Demographics II

Employment (n=301)

Work full-time

Work part-time

School full-time

School part-time

Work without pay

Not working

Total

$n$

Percent

Did not respond

$102 \quad 34 \%$

$69 \quad 23 \%$

$72 \quad 24 \%$

$20 \quad 7 \%$

$24 \quad 8 \%$

$14 \quad 5 \%$

$301 \quad 100 \%$

163

*Examples of work without pay are interning, volunteering, stay at home parenting, and art productions.

\section{Education $(\mathrm{n}=\mathbf{2 5 7})$}

Some high school

High school

20

52

Associates' or Technical Program

13

Some College

110

College degree

51

Professional degree

11

Total

257

Did not respond

207

Living Situation $(\mathrm{n}=\mathbf{2 4 1})$

Alone

13

Housemates

90

Parents or Extended Family

90

Partner 50

School 73

$30 \%$

Other

Total

Did not respond

Rent vs. Own (n=366)

Rent

Own

Other N/A

50

$14 \%$

Total

366

$100 \%$

Did not respond 
school. The age of participants ranged from 18 to 52 with a mean respondent age of 27. The demographics of focus groups were comparable to those for the survey.

\section{Age}

Over $69 \%$ of survey respondents were between the ages of 18 and 29. An unexpected finding from the survey was the number of respondents age 30 years and over. Over $30 \%$ of respondents were in this group, and $14 \%$ were age 40 or older. with three participants age 50 or older. The comments regarding age from the older generation of skaters often emphasized the physical and mental benefits of skating for long-term health. Respondents of all ages mentioned the range of ages within the

\section{Figure 4: Excerpts on Age}

I've skated almost every day for 31 years skating is my life - not just transportation or some weekend toy... I am healthier and more physically able than ALL of my peers who quit - I am stronger, faster, and more agile than anybody I know who played competitive sports in their youth or still does. -Survey Respondent

skating community at large, in the context of their own experiences learning skating skills from older friends or family, or finding mentors [It's] something I can do to remain connected with my teen boys. I reward them for B's or above with pre-dawn sessions. -Survey Respondent

within the skate community. Skaters described teaching their children to skate or learning to skate from their children. These respondents described skating as an aspect of their family transportation patterns and as a form of family bonding.

It is likely that a study open to adolescents would observe a distribution curve which skewed much younger based on the ages at which respondents reported they began skating (see Transportation Recreation Overlap). 


\section{Race and Ethnicity}

The race identity of survey respondents was $82 \%$ Caucasian, with Asian, Hispanic, Latino, and American Indian or First Nations each representing between $2 \%$ and $4 \%$ of respondents. Just over $5 \%$ of respondents identified as two or more races.

\section{Gender}

Ninety percent of survey respondents identified as male - the same percentage identified by Beal in 1996, and by Hunter's meta-analysis of recent skateboard injury demographics (Beal 6, Hunter 145). Eight percent identified as female, and $2 \%$ as a non-binary gender identity - a category which can cover a spectrum of identities not locked into the gender binary including genderqueer, transgendered, and transsexual individuals (NCTE). The percentage of nonbinary identity individuals in skating would likely vary greatly in further research due to the small sample size of this survey. However, the presence of individuals reporting non-binary identities is worth noting and worth tracking in further research so that potential data on the overlap between skating subculture and the practices and performance of gender identity do not get lost in the demographic noise.

The percentage of female skaters in this sample 1996 demographic data from Beals, which deals in some depth with gender bias within the skate

Figure 5: Excerpt on Gender

We did Sunday parkways all through Mexico and Guatemala. Down there skateboarding is a huge part of the Sunday parkways experience. City officials set up these little temporary skate parks in a plaza, like I've got photos of Guatemala City of kids doing kick flips off the pedestal of a Pope John Paul statue. These little plastic quarter pipes. But the thing I'm really remembering is in Guadalajara the gender balance was really different as well. It was a lot of young 13 to 16 year old girls in their pastel short shorts or whatever having fun on the Sunday Parkways route, having fun on skateboards. At the time it took me by surprise. It's like

"oh wow, that's not what you see in Portland".

-Focus Group Participant 
community and which is the best academic source as yet for a nuanced treatment of the topic. In a transportation context, these demographic numbers do offer some future transportation research and policy implications. There is the potential of a large latent population of female skaters who may not be "strong and fearless" - to borrow a typology used for cyclists - but who might emerge and benefit from the active transportation advantages of skating given the right social and physical environments (Dill and McNeil, Landis). Focus group responses suggested that the number of women skating - at least at organized recreational events like street skating competitions and downhill events - has been increasing in recent years. One participant recounted his international experience observing dynamic female skate cultures which suggests the potential for more women skaters in the future.

\section{Education and Employment}

Twenty-four percent of survey respondents were college graduates or above, and 31\% were current students. Fifty-seven percent were employed, five percent of were not working, and $8 \%$ were working without pay (for the purposes of this study working without pay was defined as interning, volunteering, parenting, or producing unpaid cultural content such as music albums, art shows, or films).

Narrative responses showed that many respondents used skating as a means of commuting to work or school, sometimes on its own and sometimes as part of a multi-modal trips.

\section{Living Situation}

Survey respondents spanned several life stages, and this was reflected in their reported living situations. Thirty-seven percent of respondents lived with 
housemates and $21 \%$ lived with parents or relatives, while $35 \%$ of respondents lived alone or with a partner. Sixty-three percent of respondents were renters, $23 \%$ were home owners.

\section{Financial Status}

The income of respondents was assessed using a subjective measure of financial health. There were two reasons for this. First, some writings which conflate skating, homelessness, and drug use imply that skaters have limited financial resources or are of low socioeconomic status or class identity (Lees,

Karsten and Pel,

CPTED). Using a

subjective measure of

financial wellbeing was

an effort to assess class

identity as well as

financial wealth by

allowing skaters to
Table 6: Financial Status

\begin{tabular}{|c|c|c|}
\hline & \% as Teen & \% Now \\
\hline Money was tight & $33 \%$ & $34 \%$ \\
\hline We usually did ok for money & $35 \%$ & $40 \%$ \\
\hline Money was no problem & $26 \%$ & $17 \%$ \\
\hline Prefer not to say & $5 \%$ & $8 \%$ \\
\hline Total & $\mathbf{1 0 0} \%$ & $\mathbf{1 0 0} \%$ \\
\hline Response $n$ & & \\
\hline Did not respond & $\mathbf{1 0 0}$ & $\mathbf{1 0 0}$ \\
\hline & $\mathbf{3 6 4}$ & $\mathbf{3 6 4}$ \\
\hline
\end{tabular}

respond based on their financial experiences, which may be more tightly linked with class identity than strict dollar amounts are. Second, much of the dialogue on skaters and class is focused adolescents. As dependent minors it is likely that some teens were not privy to their households' financial details. This question was designed to yield meaningful data where specific information may not be available from the participants.

Asked which best described their household's finances respondents were given a choice of "money is tight", "we usually do ok for money", or "money is no problem". Results (see table 6) showed that money was tight for only $33 \%$ of households, suggesting that the assumption that a majority of skaters are of low 
socioeconomic status are not accurate. Further research with larger samples would be useful in order to verify these results. 


\section{Advantages of Skateboarding}

One of the strongest themes to emerged from the open ended data was "many reasons to ride". Code excerpts related to this theme occurred 189 times in qualitative analysis. Nearly every excerpt explained the respondent's reasons for skating as a combination of enjoyment, exercise, utility, and community; most also mentioned either artistic expression, reduced environmental impact, financial savings, or mental and emotional benefits.

The "many reasons for skating" code emerged from two open-ended survey questions which functioned as a pre- and post-test for the reasons respondents gave for skating (for exact question order see Appendix V). "What are your reasons for riding?" was placed prior to an ordered preference question (see below) which listed some of the reasons people might decide to skate. "What are some of the advantages of skating?" was placed after the ordered preference question. The responses to these two questions were approximately equal in the breadth and detail of reasons for riding, with respondents often repeating nearly the same list for both questions. This suggests that the power of suggestion from the ordered preference question was not a strong influencing factor in respondents' perception of the advantages of skating, and that skaters' understanding of and reasons for skating are relatively stable. As with other nonmotorized modes, the choice to skate appears to be complex and multifaceted, with survey respondents listed a great many reasons for skating.

The ordered preference question which was placed between the openended prompts in the survey asked: "In thinking about skateboarding to get around, how would you prioritize your reasons for skating?". Table 7 (following page) shows priorities as ranked by respondents, with larger percentages indicating greater levels of agreement across respondents. There is a striking level of agreement in the ordering. 
To assess the similarities between skaters and cyclists this ordered response question was designed to be similar to a 2002 online survey by Stinson and Bhat investigating reasons for bicycle commuting (Stinson and Bhat 126).

\begin{tabular}{|c|c|c|c|c|c|c|c|c|}
\hline \multicolumn{7}{|c|}{ Table 7: Ordered Responses - Reasons to Skate (n=315) } \\
\hline & $\begin{array}{c}\text { Fun } \\
\text { Enjoyment }\end{array}$ & $\begin{array}{c}\text { Fitness } \\
\text { Exercise }\end{array}$ & $\begin{array}{c}\text { Practice } \\
\text { Gain Skills }\end{array}$ & $\begin{array}{c}\text { Socialization } \\
\text { Subculture }\end{array}$ & Sustainability & $\begin{array}{c}\text { Quickness } \\
\text { Speed }\end{array}$ & Convenience \\
\hline $\begin{array}{c}\text { 1st } \\
\text { Priority }\end{array}$ & $80.3 \%$ & $7.6 \%$ & $1.5 \%$ & $2.2 \%$ & $0.9 \%$ & $4.1 \%$ & $3.5 \%$ \\
\hline $\begin{array}{c}\text { 2nd } \\
\text { Priority }\end{array}$ & $10.2 \%$ & $39.0 \%$ & $21.0 \%$ & $11.7 \%$ & $1.9 \%$ & $10.7 \%$ & $5.3 \%$ \\
\hline $\begin{array}{c}\text { 3rd } \\
\text { Priority }\end{array}$ & $6.0 \%$ & $14.6 \%$ & $40.9 \%$ & $19.6 \%$ & $4.1 \%$ & $7.7 \%$ & $6.9 \%$ \\
\hline $\begin{array}{c}4 \text { th } \\
\text { Priority }\end{array}$ & $2.5 \%$ & $14.6 \%$ & $13.9 \%$ & $40.0 \%$ & $6.9 \%$ & $11.1 \%$ & $10.8 \%$ \\
\hline $\begin{array}{c}5 \text { th } \\
\text { Priority }\end{array}$ & $1.0 \%$ & $12.0 \%$ & $5.3 \%$ & $8.8 \%$ & $36.1 \%$ & $21.9 \%$ & $15.3 \%$ \\
\hline $\begin{array}{c}\text { 6th } \\
\text { Priority }\end{array}$ & $0.0 \%$ & $6.4 \%$ & $10.5 \%$ & $9.2 \%$ & $15.5 \%$ & $38.4 \%$ & $20.0 \%$ \\
\hline $\begin{array}{c}7 \text { th } \\
\text { Priority }\end{array}$ & $0.0 \%$ & $5.8 \%$ & $6.9 \%$ & $8.5 \%$ & $34.6 \%$ & $6.1 \%$ & $38.2 \%$ \\
\hline
\end{tabular}

Stinson and Bhat found that the top reasons people choose to bicycle were convenience, speed, price, and fun (ibid.). While their cyclists rated fitness and sustainability more highly than the skaters in this study, fun has the same percentage priority for both populations and skaters (who generally travel slower that cyclists as discussed below in Mode Characteristics) rated quickness as a greater reason to skate than did cyclists (see table 8). Further research comparing cycling and skating as modes might be able to identify additional mode characteristics such as speed, comfort, and intensity of exercise, which impact the order of these priorities. In general, it seemed that skating

\begin{tabular}{|c|c|c|}
\hline \multicolumn{3}{|c|}{ Table 8: Comparison to Reasons for } \\
Riding \\
& Skateboard & Bicycle* \\
\hline Fun & 80 & 80 \\
\hline Fitness & 39 & 82 \\
\hline Sustainability & 36 & 58 \\
\hline Quickness & 38 & 25 \\
\hline \multicolumn{2}{|c|}{ *From Stinson and Baht 126. } \\
\hline
\end{tabular}


emphasized more social and skills-based values and biking emphasized more ideological values. It should be noted that Stinson and Baht's question is specifically for commute trips. The skateboard data did not offer a large enough sample of commute-only riders for a direct comparison, so this more general comparison may be skewed further towards social and skill priorities than a direct commute comparison might be.

The ranking of fun in the top three reasons for skating for $96.5 \%$ of respondents may clarify some of the vagaries around the question of recreation versus transportation. Skating for transportation has elements of enjoyment in it which blur the line between recreation and transportation. While some skateboarding can be classified as travel, the boundary between utility and enjoyment will likely always be a bit fuzzy. Enjoyment and fun was the most common reason for skating qualitative responses as well. Fun was characterized as play,
Figure 6: Excerpts on Advantages

Why skate? For fun and transportation (or for fun transportation). -Survey Respondent

It's an amazing way to travel and see cities. You get to see a lot, different parts of a city than you would if you were just there walking down the main strips or whatever. You meet a lot of people. I've definitely crashed at peoples houses. You can always run into people who skate who're like "you can crash on my couch". I slept on a halfpipe in a skate shop once. It's such a tight community -Focus Group Participant

recreation, taking a break, self-expression, and satisfaction from performing skillbased moves.

There was an emphasis on fitness and exercise among skaters, with $60 \%$ of respondents ranking it in their top three reasons to ride. Stamina, strength, and cardiovascular benefits were all emphasized in survey feedback, with some mentions of weight loss, improved balance and coordination, and increased long-term fitness throughout adulthood. Respondents' attention to fitness as an aspect of their skating implies an awareness of the relationship between skating, 
travel choices, and health. Skating typifies many of the features of active transportation and skaters seem very conscious of it. This is explored in more depth in Skating as Active Transportation, below.

The skating community itself was ranked between 2 nd to 4 th priority by over $70 \%$ of respondents, and in open-ended responses it was frequently mentioned as a reason to skate. Asked who they skate with, all respondents reported skating with friends (see table 9). From long-time friends, to the ease of making new acquaintances at skate spots, to traveling nationally or internationally and discovering places to skate or to stay, the social support within skate culture emerged

\begin{tabular}{|l|c|}
\hline \multicolumn{2}{|c|}{ Table 9: Social Skating $(n=406)$} \\
\hline Skate with friends & $100 \%$ \\
\hline Skate alone & $91 \%$ \\
\hline $\begin{array}{l}\text { Skate with family (siblings, } \\
\text { parents) }\end{array}$ & $31 \%$ \\
\hline $\begin{array}{l}\text { Skate with children } \\
\text { (offspring, students) }\end{array}$ & $19 \%$ \\
\hline
\end{tabular}
as an important aspect of skateboarding.

The convenience gains associated with skating cover a range of advantages. Respondents stated that over short distances skating was their fastest and most convenient form of transportation. Many respondents cited the convenience of multi-modal integration; skateboards can be carried onto all busses, trains, and subways sometimes going where bicycles cannot. Finally, skateboards can be carried into shops, workplaces, and classrooms without concerns for parking or locking facilities. A large

Figure 7: Excerpts on Convenience

I carry my penny board (a very short skateboard) everywhere I go. I dont have a car and don't mind. The bus and my penny get me everywhere. -Survey Respondent

I no longer pay for gas or car insurance. My longboard goes everywhere with me; there is no locking it up outside for someone to possibly steal. It keeps me healthy, and its fun. Its way more manueverable than a bike, and again, its fun. -Survey Respondent number of respondents favored skating over walking for nearly all pedestrian 
trips (though the walking mode use frequencies reported in figure 35, which show that $69 \%$ of respondents walk for transportation at least weekly, somewhat contradicts this point).

Other reasons for skating were less frequent in the survey responses but still thematically strong within the data. These included sustainability, affordability and low maintenance requirements, freedom, chance to interact with surroundings, and creative self-expression.

Sustainability, affordability, and low maintenance requirements were often cited in connection with each other. The simple design and solid wheels of skateboards means

Figure 8: Excerpt on Sustainability that few parts to fail and there are few parts to replace, increasing the affordability and material sustainability of the mode. As a non-motorized mode When you're a skater you can question the environmental ethics of a biker! It's like "What're you doing with all that steel man? Look at all that rubber. Don't you love the earth?” -Focus Group Participant

the fuel sustainability and affordability are also linked.

The word 'freedom' was used with less frequency than I anticipated in the responses, replaced with more specific explanations convenience, speed, and enjoyment. When the term did arise it was typically used to define the physical sensation of skating.

Advantages described in interacting with surroundings included social interactions with passers-by and with other skaters, the chance to be outdoors, and the process of discovering new spots to practice tricks.

The rewards of creative self-expression in skating emphasized satisfaction at acquiring new skills, positive internal and peer feedback, and creative satisfaction derived from finding new ways of moving. 
The policy implications of the commonly listed advantages of skating suggest that skating could be a beneficial addition to the modes promoted for active transportation. The combination of fun and fitness in the top reasons skaters ride suggests already appreciate the rich mix of health, transportation, and enjoyment benefits which are linked with non-motorized modes.

\section{Disadvantages to Skateboarding}

Three themes emerged concerning disadvantages of skating. The first two were unexpected both in their universal emphasis and in the topics themselves.

The most problematic part of skateboarding for both focus group participants and survey respondents was poor surface conditions on roadways, sidewalks, and skating spots. Safe and comfortable skating requires smooth paving - epidemiological findings suggest that $30 \%$ of emergency room visits for skateboard-related injuries were due to irregular surfaces (Smith 121). Many different types paving problems emerged in the data. Issues included cracked and broken street paving, sidewalk slabs pushed out of alignment, paving mixes with Figure 9: Excerpts on Surface Conditions Roads smooth enough for a car or bike are not necessarily smooth enough to skate efficiently. -Survey Respondent

The smallest pebble can make you look like the biggest jackass. -Survey Respondent

[In my] home town it's legal on sidewalks only. I rarely follow this law because sidewalks are MUCH less safe than streets, and the bones I have broken skating were on sidewalks. Concrete slabs become uneven over time and create hazards for skaters.

- Focus Group Participant

oversized aggregate which caused

bumpy surfaces and uncomfortable vibrations for skaters, ruts in the roadway caused by busses and trucks, and loose stones and gravel. Skaters agreed that $1 / 2^{\prime \prime}$ to $3 / 4$ " of vertical rise was the threshold between paving variations which they could roll over and ones which posed a hazard. 
Paving quality was the greatest deciding factor for all skaters in whether to travel on streets or on sidewalks - a concern which has also emerged as significant in level-of-service studies of cyclists (Landis et al.). Skaters with experience in a range of cities also pointed out that these decisions on whether to skate on streets or sidewalks will vary depending on local paving practices.

Skaters can compensate for many of the hazards of rough streets. Focus group participants mentioned jumping their boards over uneven curbs, tree roots, or other unsafe spots order to avoid problematic surfaces, and most agreed that finding a good line to skate through roughly paved areas was generally possible. What outside viewers perceive as showing off amongst skaters is in some cases actually navigation around street hazards.

\begin{tabular}{|c|c|}
\hline \multicolumn{2}{|c|}{$\begin{array}{l}\text { Table 10: Best Seasons for Skating } \\
\qquad(\mathrm{n}=451)\end{array}$} \\
\hline Summer & $91 \%$ \\
\hline Fall & $98 \%$ \\
\hline Winter & $91 \%$ \\
\hline Spring & $37 \%$ \\
\hline
\end{tabular}

The second major theme which emerged was vulnerability to wet weather. Skateboards are made of wood and metal. Bearings are prone to rust and boards are vulnerable to water damage and warping if used in excessive rain. Respondents were generally averse to skating in rain because it was hard on their equipment and it reduced the safety and predictability of skating due to standing water or increased slickness of surfaces. Most skaters reported that in wet weather they switched to another mode of transportation - cycling, driving, and public transit were all indicated as wet weather modes. Weather appears to make skating a somewhat seasonal activity (see table 10: Best Seasons for Skating).

Weather and paving surface issues overlapped in problems with slippery pavement markings. Thermo-plastic street markings such as zebra crossings, and plasticized components including truncated domes at curb cuts were mentioned 
as hazards because wet conditions significantly altered the amount of friction skaters could exert on these surfaces before slipping became a concern.

Other disadvantages emerged, but none where given either the weight or the global emphasis as paving quality and weather. Social and institutionalized bias, conflicts with cars, and lack of safe storage space were all thematically evident.

The social biases described by skaters included shop owners and enforcement officials such as police or security guards insisting that skaters relocate, and assumptions that skaters were associated with drug and crime behaviors. Other Figure 10: Excerpts on Social Bias Skateboarder are seen as a farshot from gangbangers which is a blessing, but I'd like to see us viewed as real artists, or athletes, and less as disgruntled public offenders -Survey Respondent

Skateboarders are treated as if they are guilty of more than just skateboarding. -Survey Respondent

actions occurred either indirectly through community pressure towards increased enforcement of anti-skate regulations, or physically through anti-skate hardware. Sometimes these fears actually preceded any skater presence, as with hardware installations at unskatable sites.

Most conflicts with cars originated in disagreements over sharing the road. Skaters reported that drivers were often confused or angered by skaters' presence on streets, independent of the amount of right-of-way available for both modes to travel. Another issue mentioned by survey respondents

\author{
'Figure 11: Excerpts on A Place for Skaters \\ skateboarding in the pedestrian/automobile \\ ecosystem. \\ -Survey Respondent \\ People often don't give you the right of way, \\ or think you are being a nuisance, when you \\ are really just commuting. \\ -Survey Respondent \\ Bike lanes preferred - less pedestrians and \\ bike riders tend to be more aware of their \\ sorroundings. \\ -Survey Respondent
}


and explored in more depth with focus group participants was the signaling and body language of traveling skaters and perceptions of these motions by cars (for more see Safety sections, below). Skaters have many different ways of compensating for their unexpected presence as road users. Some choose to skate on sidewalks, others favor bike lanes, while some take the motor vehicle lane. Attitudes towards conflicts between drivers and skaters ranged from complacent to mischievous. However, the majority of respondents favored skating on lowtraffic streets where all forms of conflict with cars is minimized based by route choice.

The lack of secure storage for skateboards emerged as the flip-side of the convenience of carrying boards and not needing dedicated parking. While skateboards can be carried onto busses and into classrooms the can be a burden to carry and a challenge to store. Secure storage for skateboards is uncommon, and larger boards are unwieldy in the confined spaces such as trains, shops, and offices.

Policy implications of self-reported disadvantages of skating include an increased awareness of paving quality and skaters' vulnerability to rough or broken surfaces, and also bringing skaters into currently unfolding conversations of what defines a road user and how to move towards a mix of modes sharing the right-of-way safely and civilly.

\section{Built Environment Advantages and Barriers}

Survey respondents were asked to assess features of the built environment, road structure, and traffic, and rate them as advantages, barriers, or features which did not matter to the quality of their skating experience (see figure 3 and table 11). The categories included in this question were established 
by observing skaters interact with the built environment, and it includes a mix factors including infrastructure, other road users, and terrain types.

Responses were quite consistent across most categories, and with some respondents noting that the differing preference were partially attributable to the use of shorter boards used for street skating or tricks compared to longboards set up for cruising, or very small penny boards (see table 11: Skateboard Types, below in Travel Characteristics). As expected from the data above on disadvantages of skating there was strong agreement in need for smooth streets and

\begin{tabular}{|l|c|c|c|}
\hline \multicolumn{4}{|c}{ Table 11: Advantages and Barriers $(n=307)$} \\
\hline & Advantage & Barrier & Doesn't matte \\
\hline Street - smooth & $97 \%$ & $0 \%$ & $2 \%$ \\
\hline Downhill - mild & $94 \%$ & $0 \%$ & $6 \%$ \\
\hline Sidewalk - smooth & $93 \%$ & $1 \%$ & $6 \%$ \\
\hline Downhill - steep & $77 \%$ & $12 \%$ & $10 \%$ \\
\hline Bike lanes & $67 \%$ & $4 \%$ & $28 \%$ \\
\hline Curb ramps & $68 \%$ & $5 \%$ & $28 \%$ \\
\hline Other skaters & $50 \%$ & $2 \%$ & $47 \%$ \\
\hline Auto traffic - light & $36 \%$ & $17 \%$ & $47 \%$ \\
\hline Bicyclists & $13 \%$ & $21 \%$ & $65 \%$ \\
\hline Uphill - mild & $9 \%$ & $23 \%$ & $67 \%$ \\
\hline Auto traffic - heavy & $6 \%$ & $63 \%$ & $31 \%$ \\
\hline Street - rough & $7 \%$ & $69 \%$ & $24 \%$ \\
\hline Sidewalk - rough & $4 \%$ & $71 \%$ & $25 \%$ \\
\hline Uphill - steep & $4 \%$ & $75 \%$ & $21 \%$ \\
\hline
\end{tabular}
sidewalks, which more than $93 \%$ of respondents agreed advantages, and against rough streets and sidewalks, which over $70 \%$ of respondents categorized as barriers. Also interesting in these findings are the $67 \%$ agreement on bike lanes as a useful part of the streetscape many skaters reported feeling safe skating in bike lanes.

Planning implications here suggest that skateboards and bikes could possibly be combined when planning route networks, since both modes are sensitive to hills and traffic, and since a majority of skaters are able to find a safe space to travel in bike lanes. 


\section{Transportation Characteristics of Skateboards}

Survey respondents and focus group participants agreed on some basic travel characteristics of skateboarders. The speed of skateboards when being used for transportation was reported as approximately 8 to $15 \mathrm{mph}$. Variations were mainly due to whether the skateboard set-ups were optimized for travel or for other uses such as tricks. The

\begin{tabular}{|c|c|c|c|}
\hline \multicolumn{4}{|c|}{ Table 12: Skateboard Types $(\mathbf{n = 4 5 6})$} \\
\hline & Usually & Sometimes & Never \\
\hline Skateboard & $45 \%$ & $33 \%$ & $15 \%$ \\
\hline Longboard & $44 \%$ & $12 \%$ & $33 \%$ \\
\hline Other & $11 \%$ & $4 \%$ & $0 \%$ \\
\hline
\end{tabular}
size and hardness of skateboard wheels, street grade, and to the amount of pushing or pumping being used to generate speed were all variables which influenced speed. One transportation-only longboarder reported skating 4$10 \mathrm{mph}$ while others specializing in downhill runs clocked speeds above $40 \mathrm{mph}$. Even when skateboarding speeds barely exceed walking or are similar to biking skaters seemed to agree that it was more fun to skate than to walk or bike.

Viable trip lengths were reported as ranging from 1 to 4 miles one way. Survey responses suggest that skating is useful for trips of up to two miles for all types of riders. For longer trips the impacts of board design begins to be felt. The smaller boards used for street skating, as well as the ultra-small popsicle-stick boards which have become popular in recent years are more suited to shorter distances while longboards and cruisers, built for rougher terrain and a smooth ride at higher speeds, could sustain longer trips (for further information on ridership levels in this study see table 12, and on the difference between board types see Appendix I: Glossary). To illuminate the capacity of longboards, two of the specialized recreational events developed by longboarders are "hill bombing" consisting of long downhill runs reminiscent of snowboard runs at a conventional ski slope, and long distance races including marathon- and 100mile distances (PDX Downhill, Skate Further). In a transportation context these 
are the boards likely to sustain full commute trips while the smaller, lighter, more responsive street skateboards are more likely utilized for multi-modal trips and short neighborhood trips.

Focus group participants compared the pros and cons of skating to the pros and cons of other modes

\begin{tabular}{|c|c|c|}
\hline \multicolumn{3}{|c|}{$\begin{array}{l}\text { Table 13: Skateboarding Compared to } \\
\text { Other Active Modes - Focus Group Data }\end{array}$} \\
\hline & $\begin{array}{l}\text { Compared to } \\
\text { Cycling }\end{array}$ & $\begin{array}{l}\text { Compared to } \\
\text { Walking }\end{array}$ \\
\hline Fun & more fun & more fun \\
\hline Speed & slower & faster \\
\hline Convenient & more convenient & no data \\
\hline Boring & no data & less boring \\
\hline Tiring & more tiring & less tiring \\
\hline
\end{tabular}
(see table 13). Most agreed that bikes were faster than skateboards, and less tiring. The provision of secure bike racks was also mentioned as an asset unavailable to skaters. However, skateboards were typically preferred as a more fun and creative to ride, the ease of multimodal trips were frequently mentioned, ease of switching modes, storing, carrying skateboard were frequently emphasized.

A great number of survey respondents preferred skating to walking for two simple reasons: it was faster, and it wasn't boring. Focus group participants elaborated, describing skating as a way to take ownership or enjoyment of trips which - especially as teenagers - sometimes felt like obligations beyond their control, such as traveling to school or to visit extended family. They described carrying their skateboards as a way to inject some unexpected fun and recreation in substitute for travel trips.

\section{Figure 12: Excerpt on Tricks in Travel} Skating as transportation also allows you to utilize tricks in "the real world". In other words, tricks you've worked on for 4 hours every day now have practical use. -Survev Resnondent

Responses describing how skaters interacted with the streetscape shed some additional light on these findings. The quality of riding surface is very important for skating. Skaters described rough or broken paving as a key cause 
of accidents and injuries. The simplest way for skaters to avoid a paving irregularity such as a pothole, or to transition across a curb from street to sidewalk, is to use trick maneuvers that shift their weight on the skateboard or that lift it off the ground. Therefore tricks - which are typically viewed as skating for recreation - are actually key transportation skills for many skaters.

The policy implications of skateboarders' travel characteristics center around finding a space for skateboarders within our current road user policy, but their defining similarities and differences from other modes. The speed and range reported for skateboarders were similar enough to bicycles that it's possible the two modes could be addressed together for planning, infrastructure, and policy purposes. The breadth of experiences in trip length and pavement quality suggests that any project or policy considering skaters should make a point to reach out to both longboarders and skaters using shorter boards for their feedback.

\section{Overlap of Transportation and Recreation Uses}

The survey collected information about the types of riding skaters do, both as recreation and for transportation. This question was designed as a way to develop an understanding of the degree to which recreation and transportation uses overlap for individual riders, as well as whether skating as transportation may be utilized differently by skaters at various life stages.

For non-motorized modes in general the question of the degree of overlap between recreational users and transportation users is still in its initial research phases. Some publications assumes that shifts from recreation to transportation uses are likely. A study of cyclists at a University of South Australia campus conducted focus groups which segmented commuters from recreational cyclists; while the aim of the study was to create policy suggestions for increasing bike 
commute mode shares there was no discussion of what changes might convert recreational riders into commuters - the authors simply argued that individuals who already had all the necessary equipment for cycling were good candidates for conversion (Bonham and Koth 97). The assumption that recreational riders become transportation riders appears in policy publications as well. The City of Toronto Bike Plan argued that the high rates of recreational riding in survey findings represented latent demand for bicycle commuting infrastructure (City of Toronto Bike Plan 2-5). However, some finding show that recreation and transportation attract discrete populations. A study of Portland, OR cyclists published in 2007 found that utilitarian riders tended to be younger than recreational cyclists, and that those with higher incomes were: "most likely to be regular cyclists, but were not more likely to ride for utilitarian purposes" (Dill and Voros, 12). Karsten and Pel's observations of Dutch skaters showed that skaters carried their skateboards on their bicycles between skateparks suggesting that even when the means to skate for both recreation and transportation is available one type of use may dominate for some skaters (336). In order to address the vagaries of this question the survey asked participants to note the ages at which they began skateboarding for various purposes (see table 14).

In order to build an initial understanding of how and why participants were skating, the survey collected start and stop ages for four different types of skating: practicing tricks; participating in skateboarding subculture or skating to be part of the skate community; spending time at skate spots or skateparks, and skating for transportation. While the skate community can encompass a range of types of skating, the ethnographic literature suggested that community was such a significant aspect of skating that it was included just in case any age-related data emerged. Some of these categories overlap (e.g. Practicing tricks at the 
skatepark with other members of your skating community).

However, some slight variations did emerge.

Data

from this

\begin{tabular}{|c|c|c|c|c|c|}
\hline \multicolumn{7}{|c|}{ Table 14: Overlap of Types of Skating } \\
\hline Tricks & Community & Skatepark & Transportation & $\%$ & $n$ \\
\hline$\checkmark$ & $\checkmark$ & $\checkmark$ & $\checkmark$ & $86.2 \%$ & 287 \\
\hline & $\checkmark$ & & $\checkmark$ & $5.7 \%$ & 19 \\
\hline & $\checkmark$ & $\checkmark$ & $\checkmark$ & $2.1 \%$ & 7 \\
\hline & $\checkmark$ & & $\checkmark$ & $1.8 \%$ & 6 \\
\hline$\checkmark$ & $\checkmark$ & & & $1.5 \%$ & 5 \\
\hline$\checkmark$ & & $\checkmark$ & $\checkmark$ & $1.2 \%$ & 4 \\
\hline$\checkmark$ & & & $\checkmark$ & $<0.1 \%$ & 3 \\
\hline & & & $\checkmark$ & $<0.1 \%$ & 2 \\
\hline Total & & & & & 333 \\
\hline \multicolumn{7}{|c|}{ Did not respond } & & 131 \\
\hline
\end{tabular}

question suggests that there is an extensive overlap between recreation and transportation uses among skaters. Of the 333 skaters who responded to this survey question 287 - over $85 \%$ - reported skating for all four reasons. Over 5\% did not use skateparks but practiced tricks, skated for transportation, and were part of the skate community. Over two percent did not practice tricks but participated in the other three aspects of skating listed, and less than $0.1 \%$ of question respondents participated in two or fewer types of skating. This suggests that, among people who skate for transportation, there is still a high amount of recreational being practiced.

Many respondents started practicing tricks at a younger age (mean start age $=13.9$ years) and skating for transportation when they were slightly older (mean start age $=15.9$ ). These data suggest a progression from street skating to transportation uses for some riders, with more people beginning to skate for transportation at ages above mid-adolescence (see tables 14 and 15, and figure 5). Many respondents described practicing tricks and street skating with social groups during early adolescence, reduced interest among some skaters with the acquisition of a drivers license, and a renew interest in skating as young adults especially as transportation while attending higher education or working in food 
Table 15: Types of Skating by Age/Number of Years Skating

\begin{tabular}{|c|c|c|c|c|c|c|c|c|}
\hline & $n$ & $\%$ & $n$ & $\%$ & $n$ & $\%$ & $n$ & $\%$ \\
\hline \multicolumn{9}{|l|}{ Age Started } \\
\hline & \multicolumn{2}{|c|}{ Tricks } & \multicolumn{2}{|c|}{ Community } & \multicolumn{2}{|c|}{ Skateparks } & \multicolumn{2}{|c|}{ Transportation } \\
\hline $4-7$ & 14 & $4 \%$ & 9 & $3 \%$ & 5 & $2 \%$ & 9 & $3 \%$ \\
\hline $8-11$ & 95 & $30 \%$ & 64 & $20 \%$ & 51 & $17 \%$ & 45 & $14 \%$ \\
\hline $12-15$ & 134 & $42 \%$ & 153 & $47 \%$ & 138 & $45 \%$ & 131 & $40 \%$ \\
\hline $16-19$ & 43 & $14 \%$ & 63 & $19 \%$ & 67 & $22 \%$ & 87 & $27 \%$ \\
\hline $20-23$ & 14 & $4 \%$ & 16 & $5 \%$ & 21 & $7 \%$ & 22 & $7 \%$ \\
\hline $24-27$ & 6 & $2 \%$ & 11 & $3 \%$ & 8 & $3 \%$ & 14 & $4 \%$ \\
\hline $28-31$ & 5 & $2 \%$ & 3 & $1 \%$ & 5 & $2 \%$ & 5 & $2 \%$ \\
\hline 32 or older & 6 & $2 \%$ & 7 & $2 \%$ & 9 & $3 \%$ & 14 & $4 \%$ \\
\hline Total & 317 & & 326 & & 304 & & 327 & \\
\hline Did not respond & 147 & & 138 & & 160 & & 137 & \\
\hline Mean start age & 13.9 & & 14.4 & & 15.3 & & 15.9 & \\
\hline \multicolumn{9}{|l|}{$\begin{array}{l}\text { Number of Years } \\
\text { Skating }\end{array}$} \\
\hline & \multicolumn{2}{|c|}{ Tricks } & \multicolumn{2}{|c|}{ Community } & \multicolumn{2}{|c|}{ Skateparks } & \multicolumn{2}{|c|}{ Transportation } \\
\hline 3 years or less & 8 & $15 \%$ & 9 & $16 \%$ & 9 & $17 \%$ & 10 & $22 \%$ \\
\hline $4-7$ & 20 & $37 \%$ & 19 & $34 \%$ & 21 & $40 \%$ & 8 & $17 \%$ \\
\hline $8-11$ & 6 & $11 \%$ & 8 & $14 \%$ & 6 & $12 \%$ & 8 & $17 \%$ \\
\hline $12-15$ & 6 & $11 \%$ & 5 & $9 \%$ & 5 & $10 \%$ & 4 & $9 \%$ \\
\hline $16-19$ & 1 & $2 \%$ & 6 & $11 \%$ & 3 & $6 \%$ & 5 & $11 \%$ \\
\hline 20 years or more & 8 & $15 \%$ & 5 & $9 \%$ & 2 & $4 \%$ & 4 & $9 \%$ \\
\hline Total & 54 & & 56 & & 52 & & 46 & \\
\hline Did not respond & 410 & & 408 & & 412 & & 418 & \\
\hline Mean years & 9.3 & & 9.4 & & 5.9 & & 5.4 & \\
\hline
\end{tabular}

service or other jobs with odd hours. While the available data did not show large patterns in ridership matching these descriptions, a more fine-grained study of life stage and skating may turn up interesting age-related patterns. Perhaps skaters who spent their leisure time practicing tricks as adolescents are, as adults, able to fit skating into different parts of their lives, retaining the feeling of "travel for the fun of it" and redirecting it for a more utilitarian purpose (Mokhtarian and Salomon 31).

The number of years respondents reported skating were high relative to respondents' ages, but with an average reported start age for skating in general 
Figure 13: Tricks and Transportation - Age Started

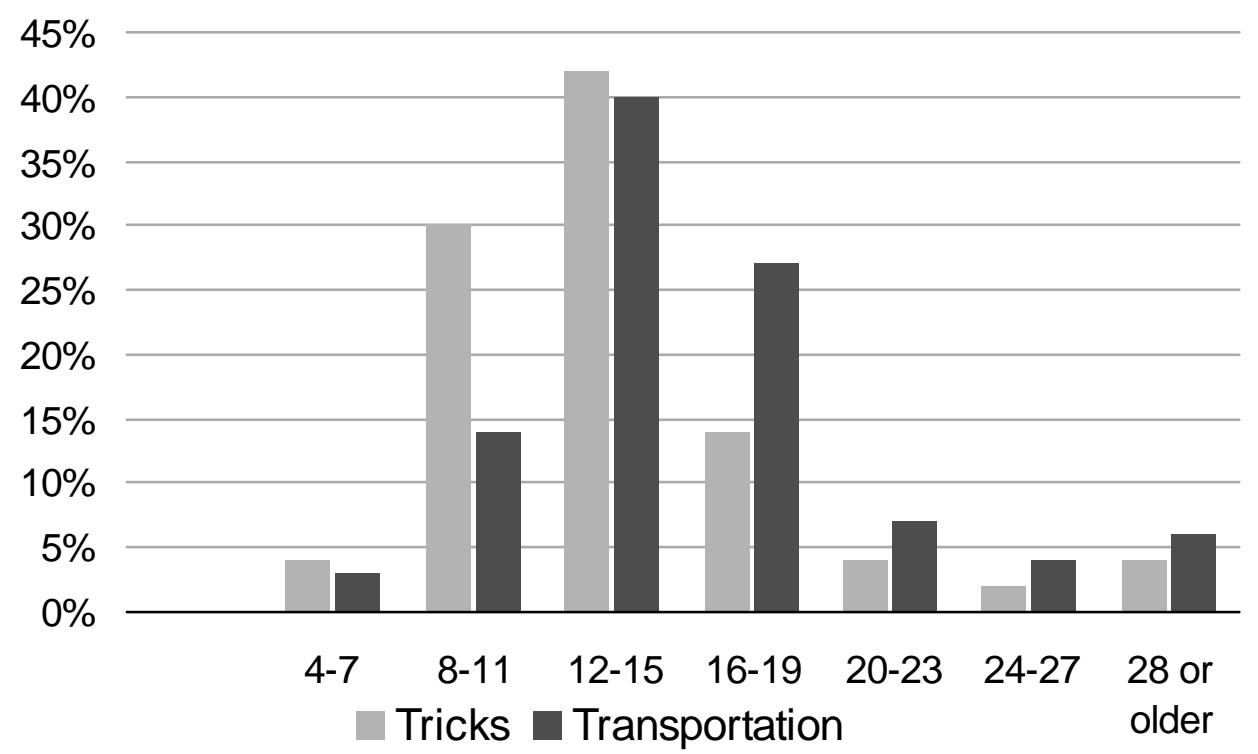

as 11.7 years (possibly confined to driveways at first since most skaters reported beginning specific types of skater later) it is logical that even the youngest survey respondents would have been skating for several years. Again, the number of years skating to practice tricks and as part of the skateboarding subculture is considerably longer than the time spent skating for transportation, suggesting that skaters may utilize the practical aspects of skating at a later age.

This data offers a couple of policy implications. First, it suggests that cities with large populations of skaters practicing tricks or doing street skating are likely to have at least some

Figure 14: Excerpt on Life Stage

Skating took the secondary position in my life as soon I acquired my license at age of 16. From here on out it was easier to commute to my friend's homes by vehicle rather than skateboard ... my life 'sped-up', and my boundaries broadened for the distances I could regularly travel. Skateboarding came back in as a primary activity freshman year of college, in order to commute from my dorm to class. Waking up and skating to class was a refreshing spin on a weekly routine, and also kept navigating a certain area interesting, as I could take different routes \& learn the concrete. During these periods skating kept tension and stress off, and also allowed me to maintain physical activity as it was embedded within my schedule.

-Survey Respondent 
people utilizing skating for transportation even if those populations are less noticeable. Second, it's suggests that in many cases individuals who are skating for transportation are already at ease on their skateboards, thus reducing some of the safety concerns associated with new riders (see Safety - Danger and Injury, below).

\section{Mode Uses and Multi-Modal Data}

Collecting basic mode use data and demographics together could help develop an initial picture of the skateboarding population and their behaviors. There is still some distance to go before tracking skateboarding as transportation mode becomes common practice, even in research on skating itself. Skateboarding is mentioned in an 'other' mode share category in a handful of studies. A study of active transportation for school trips among teenagers included skateboarding as a transportation option but did not track it as a separate mode (Babey et al. 207). A public health study of 4th- and 5th-grade students found that those who were regular active commuters for school trips had body mass index and skin-fold measurement that were lower by a statistically significant margin than those who were not regular active commuters - skating was defined as an active commute type for the study, and tracked in a combined group with pedestrians and cyclists (Rosenberg et al. 1772). Helen Woolley, one of the most frequently cited researchers on skateboarding in the geography and urban design literatures, did not include skateboarding as a separate travel mode in the participant demographics of focus group she held to discuss skateboarding. She wrote that "Forty-three per cent of the respondents had travelled [to the focus group] by bus, $26 \%$ had walked or 
skated, and $22 \%$ had arrived at the meeting by bicycle" (Woolley 216). ${ }^{5}$ Other studies of skateboarders did not investigate it as a mode of transportation, so no mode use demographics are available.

Survey respondents reported using a mix of different modes when asked "in all the trips you make around town (not just skating) how often do you get around by [list of mode options" (see table 16). Daily and weekly use rates for skateboard and autos were similar, with autos used weekly or more by $75 \%$ of respondents and skateboards used weekly or more by $82 \%$ of respondents. Daily or weekly rates decreased from there for walking Figure 15: Excerpts on Skating and Other Modes Bikes and public transportation go hand in hand with skateboards. Skateboards tie up the loose ends of public transportation and the clumsy size and security of the bike making covering shorter distance useful. -Survey Respondent

For me skateboarding is awesome because it tightens transit. And it's preferable to a bike because I can bring it onto the bus and just kind of become a pedestrian.

-Focus Group Participant $(69 \%)$, using transit (38\%), and

cycling (27\%), though these mode splits are still quite large. The relatively high use rates for bike or car share programs, with approximately $15 \%$ of respondents

\begin{tabular}{|c|c|c|c|c|c|c|c|}
\hline \multicolumn{8}{|c|}{ Table 16: Mode Use Frequencies $(n=304)$} \\
\hline & Skate & Auto & Walk & Transit & Bike & $\begin{array}{l}\text { Motor } \\
\text { Bike }\end{array}$ & $\begin{array}{c}\text { Car or Bike } \\
\text { Share }\end{array}$ \\
\hline most days & $45.1 \%$ & $43.8 \%$ & $36.2 \%$ & $20.9 \%$ & $11.9 \%$ & $1.5 \%$ & $2.6 \%$ \\
\hline at least weekly & $37.3 \%$ & $31.3 \%$ & $32.8 \%$ & $17.8 \%$ & $16.4 \%$ & $3.6 \%$ & $6.3 \%$ \\
\hline $\begin{array}{l}\text { at least } \\
\text { monthly }\end{array}$ & $10.7 \%$ & $11.8 \%$ & $14.8 \%$ & $16.7 \%$ & $17.8 \%$ & $2.2 \%$ & $5.9 \%$ \\
\hline $\begin{array}{c}\text { at least } 6 \\
\text { months }\end{array}$ & $4.5 \%$ & $4.3 \%$ & $7.2 \%$ & $20.9 \%$ & $17.8 \%$ & $5.5 \%$ & $2.6 \%$ \\
\hline never & $2.3 \%$ & $8.9 \%$ & $9.0 \%$ & $23.7 \%$ & $36.0 \%$ & $87.3 \%$ & $82.7 \%$ \\
\hline
\end{tabular}

${ }^{5}$ For the good of the record, $76 \%$ of focus group participants for this research arrived with skateboards. 
using a these services monthly or more, is an interesting subject for further research; skateboarders could be a useful demographic to track for studies on the utilization of share programs as part of multi-modal transportation behaviors.

For many participants skating was integrated into their transit use as a last mile solution. Qualitative analysis of multi-modal trip descriptions identified 423 code excerpts encompassing bus, car, train, and other combined trips. A majority of respondents described the complementary nature of skating and public transit as an advantage for skaters. Often skating was tightly coupled with their use of transit. Many respondents described carrying their skateboards on busses or trains and then trip-chaining for various tasks in the downtown core or another dense center before taking transit home again, perhaps skating the final distance between the transit stop and residence. This behavior linked in with two codes especially: better than walking described many participants' preference for skating distances which were walkable, due to skating being quicker, more fun, and more interesting; and easy to carry described the simple transitions from skating to pedestrian or transit rider roles.

Three types of multi-modal skate practices emerged. First are the public transportation integrated skaters. They typically use skateboards to address the last mile problem, skating in their home neighborhood to transit and then in destination areas or between transit connections. Next is the urban destinations skater, who takes another mode to a given destination
Figure 16: Excerpts on Three MultiModal Types

I lived towards the top of a hill and I found riding my skateboard down the hill was the quickest way to get to the bus stop. -Survey Respondent

I can fit a longboard in my car easily and park outside of the major downtown areas for free and commute to University by board. -Survey Respondent

The skateparks in my area are nearly impossible to get to on a skateboard due to traffic and lack of sidewalks, and you often have to get off your board to walk a portion of the way. - Survey Respondent 
(most frequently private car to downtown or near a college campus) and then skates within the urban core for several hours while conducting errands, work, school or other duties. Typically in this case the skateboard is both a means of efficient transportation over short distances and a way to avoid parking costs in the core. Finally there is the trick destination skaters. These skaters regularly travel to skate spots or skate parks by public transportation or by private car, for the purpose of recreational riding. It is notable that many people mentioned this practice, and that several also mentioned that official skate parks are sited often in spots which are disconnected from streets which are safe to skate on, making them hard to reach by skateboard alone.

The policy implications of skateboarding here are promising. Skating integrates easily with transit, allowing riders to bring their ride with them on busses, subways, or trains - the option most preferred by $60 \%$ of bike commuters in a 2010 study of combined cycling and transit trips in Montreal (BachandMarleau et al, 113). For skateboarders this benefit extends to transit systems where space for bicycles is limited or nonexistent due to existing facility design.

Skating is also a ready solution to the last mile problem. For transit agencies, municipalities, and other groups working to expand transit access skaters may be an existing unidentified component of multimodal ridership or might offer new user base for collaboration.

As a transportation mode, skateboarding has a short history and a small population. It has the potential to be a highly utilitarian mode but its share will likely always be small. However, some travel behaviors appear to be consistent enough across the skating population that findings on travel behavior and mode use can be relied on as usable data. 


\section{Route Choice}

Route choice preferences were collected in focus groups, using an activity where participants marked their preferred skateboard routes on a street map. The activity was designed to facilitate casual conversation amongst participants, giving them a chance to re-focus part way through the interview, as Colucci suggests is good practice with younger focus group participants (Colucci 1424). The visual reference also helped participants analyze their own behaviors by presenting visual route data from which they drew examples and comparisons.

A clear consensus of route feature prioritization emerged within focus groups. A good skate route has three main features: good street surface, low traffic volume, and gentle grade changes.

Street surface quality was important to all skaters. The types of poor quality surfaces and problems with skate surfaces were consistent with survey findings reported in the Disadvantages section and the graph of Advantages and Barriers, above.

Low traffic volumes were a priority for most participants, mostly as a way to reduce conflict with other modes. Participants agreed that low traffic streets were generally preferable to

Figure 17: Excerpt on Grade sidewalks, since they gave skaters enough room to move side to side for breaking and other maneuvers.
Skateboards aren't so good moving uphill. Even though a slight uphill push isn't bad, momentum is key with skateboarding. With the right terrain and transition, skateboarders can move at high speeds comfortably, and almost effortlessly. -Survey Respondent

Gentle grade change was

prioritized by skaters because pushing or accelerating on a skateboard demands high energy inputs. This finding was supported by survey data covered in Advantages and Barriers.

Route choice did vary by the type of skating practiced. Longboarders and frequent transportation skaters tended to use the same routes for trip after trip, 
with one transportation-only skater explaining: "Maybe I'll deviate a block or two but skateboarding is utilitarian. I look for neighborhood greenways or low traffic streets with good crossings on arterials first. I look for sidewalks second, and I look for bike lanes as my third options." Skaters using their boards for transportation but who came from a street or trick skating background tended to explore more varied routes. As one skater said: "I'll do a similar route for a while and then 'how else Figure 18: Excerpt on Finding Skate Spots "When I'm skating [for transportation] I stop and skate stuff [tricks]. And people don't look at you like you're commuting they look at you like you're a freak. It's awesome! -Focus Group Participant

can I get there' I'll find something else

every time. And there's a really cool bank or concrete thing in front of somebody's house that I can bash into or play around". This skater said that the reward of finding new obstacles or spots to skate was often greater than taking routes he knew were good.

Bike boulevards - at least Portland's neighborhood greenways - were somewhat favored among focus group participants, who reported that the routes tended to have good quality pavement, and were useful for Figure 19: Excerpt on Bike Boulevards "Some I feel like there's more traffic on the bike routes. They usually do have pretty good pavements."

-Focus Group Participant

traveling from place to place quickly.

Policy outcomes from the route prioritizations reported by skaters suggests that the needs of skateboarders are quite similar to those of cyclists. It is possible that these two populations could be grouped for purposes of road infrastructure planning. Existing tools for assessing and expanding cyclists' comfort and safety could also be used as initial proxy measures of skatable travel routes. It may be possible to use Gellar's typology of four types of cyclists to 
further understand the comfort and safety needs of skateboarders, and to improve conditions for risk-averse riders. (Dill and McNeil, Garrard et al.)

\section{Safety - Perceptions and Practices}

Study participants generally regarded skating for transportation as a safe practice. Participants stated that recreational skating - such as learning new tricks or participating in downhill races - had a greater likelihood of falls and injuries than skating for transportation. The primary reason respondents viewed skating for transportation as safe was the great degree of control and agility they had on their boards. Participants emphasized that safe skating for transportation depended on skill and familiarity with skating, and that level of experience greatly influenced skater safety. This claim

is substantiated by a data set from the early days of assessing skate safety, when a review of skateboard injuries published in the Canadian Medical Association Journal found that a third of emergency room visits were by people who had been skating for a week or less (Smith 121). Another epidemiological study found that injuries occurred more often at "the younger end of the scale, between 10 and 15 " years of age, when skaters would not

\section{Figure 20: Excerpt on Exerpeince}

Some people think that every skateboarder is at every moment risking the chance of breaking their neck or splitting their head open. This is so wrong. Skateboarders are comfortable doing what they do because they know what they are doing . . . To think that a skater is living on that edge all the time is a bit flattering, but wrong nonetheless. We spend thousands of hours on our boards. It's practically walking for us. With the right weather conditions, board, and a well known route, I would put my safe arrival rate at $99.99 \%$. The .01\% is someone running a red light and creaming me with their Cadillac.

- Survey Respondent

have logged as many hours on their boards (Hunter 145). Compared to walking skaters described being able to move more quickly to avoid dangers. Compared to biking they stated that it was easier to accurately change direction and speed on a skateboard. Falling from skateboards also compared favorably to falling 
from a bicycle, since there was less chance of becoming entangled with equipment. Skaters also mentioned that knowing how to fall safely was an added safety aspect of skating for transportation; while falling is relatively infrequent event for most pedestrians or cyclists, skaters claimed that the muscle memory and reaction times they developed as street skaters kept them safer when they did fall no matter the type of skating. Two common assumptions about skaters which survey and focus group and survey participants were keen to debunk were that skaters were either out of Figure 21: Excerpt on Signals control at all times, or that their movements were unpredictable and unplanned. Pedestrians tended to freeze and stop walking rather than assume that skaters were able to skate around them. Drivers often seemed to assume that skaters were out of control. NonWe need to teach drivers to read body language on pedestrians, bikers, boards roller blades, all of it. Also, more signals would benefit as well, if a driver knew my signal for shutting down (stopping at high speeds using a slide glove) and knew what to expect when they see the process happening, it would be safer for everyone. A shut down, to someone unfamiliar with the process, can look like an uncontrollable bail. But its not. - Survey Respondent

skaters often assumed that, because skateboards have no visible break mechanism, they have no way of stopping.

One important aspect of perceived safety appears to be the unique body language of skating. There are several differences in movement patterns between skaters and other modes. Autos, bicycles, and pedestrians typically move forward in straight lines. Skaters require more lateral room than other modes as they use side to side pumping and slide techniques to increase and reduce speed (for definitions see Appendix I, Glossary). Skaters' movements are also more dynamic than other non-motorized modes due to the full-body movements of pushing and balancing, so normal skate movements are sometimes interpreted by other road users as accidents in progress. A few key maneuvers skaters use specifically to regulate their speed or to break appear to be viewed with special 
mystification by drivers. Slowing and stopping techniques where the rear of the skateboard is brought out to the side (such as is commonly seen in snowboarders) are often used for 'shutting down' or stopping, but participants reported that these techniques are interpreted as skids or falls by many drivers. Foot breaking, where the pusher foot rests on the pavement to create drag and slow the skater, also confused road users. ${ }^{6}$ Participants reported that both types of breaking had been consistently misinterpreted by nonskaters as accidents-in-progress.

Figure 22: Excerpt on Safe Stopping

One of the big things is "well there's no brakes. You can't stop." Obviously there are ways to stop. It's different than a bicycle but we don't just stand at the top of a hill and go "whatever, YOLO"."

-Focus Group Participant

The policy implications from these data suggest that, in any assessment of transportation safety which includes skateboarders, mode users should be consulted directly and their expertise should be utilized in developing an accurate understanding of risks associated with skating. There is also a possibility for increasing the comfort of other road users through education about skating behavior and the typical range of movements utilized by skaters.

\section{Safety - Danger and Injury}

The sources of danger reported by skaters differ from non-skaters' perceived dangers of skating. The skateboard injuries described by respondents were most often falls attributed to poor paved surfaces, and collisions with pedestrians or cars were not cited as frequent causes of injuries. Epidemiological studies of skating-related injuries confirm this finding (Tominaga et al.; Hunter;

\footnotetext{
${ }^{6}$ The video Safety Huey Ep. 1 - Arlington Heights demonstrates foot breaking, a sliding stop, and shutting down at timestamp 2:49)

*YOLO is an acronym for You Only Live Once, currently in common usage, often used as a "justification to do dangerous or harmful things" (Zimmer).
} 
Smith). Compared to other forms of recreation skating is safer than it is perhaps perceived, as well. Hunter's epidemiological research on sports injuries, which found that for skateboarding: "rates of injuries treated in emergency departments (8.9 per thousand participants) ... Were significantly lower than those for basketball (21.2) and football (20.7), and also lower than rates for bicycling (11.5), and snowboarding (11.2) (Hunter, 155). Meta-analysis of skating injuries found that the majority of injuries are fractures and sprains, occurring most frequently in upper extremities (Inoue et al 2009, Hunter, 2012). For injuries requiring a hospital visit fewer than $5 \%$ were head injuries, and resulting recommendations prioritize elbow and wrist protection ahead of helmets from an epidemiological standpoint (Schieber et al. 1994).

Many respondents include conflicts with cars in their descriptions of disadvantages of skating, but those conflicts appear to be mainly social. Only one description of a skater/auto accident emerged in the course of this research - that case involved a car hitting and damaging a skateboard. The rider was not injured.

Other safety concerns reported by skaters were similar to those of cyclists - skaters bodies are vulnerable in case of accidents, roadways in poor condition can be hazardous for skaters, and while protective gear is available use rates are relatively low (see table 17) the bans on skating in many cities sometimes encourages people to bypass night-time visibility equipment in order to skate undetected.

$$
\begin{aligned}
& \quad \text { Survey } \\
& \text { respondents } \\
& \text { reported low } \\
& \text { levels of use for } \\
& \text { most safety }
\end{aligned}
$$

\begin{tabular}{|c|c|c|c|c|c|c|}
\hline \multicolumn{7}{|c|}{ Table 17: Safety Equipment Rates of Use (n=315) } \\
\hline & Helmet & $\begin{array}{c}\text { Slide } \\
\text { Gloves }\end{array}$ & $\begin{array}{c}\text { Elbow } \\
\text { Pads }\end{array}$ & $\begin{array}{c}\text { Knee } \\
\text { Pads }\end{array}$ & $\begin{array}{c}\text { Wrist } \\
\text { Guards }\end{array}$ & $\begin{array}{c}\text { Lights or } \\
\text { Reflectors }\end{array}$ \\
\hline Always & $22 \%$ & $9 \%$ & $3 \%$ & $2 \%$ & $0 \%$ & $3 \%$ \\
\hline Usually & $10 \%$ & $11 \%$ & $0 \%$ & $5 \%$ & $2 \%$ & $4 \%$ \\
\hline Sometimes & $14 \%$ & $20 \%$ & $13 \%$ & $20 \%$ & $6 \%$ & $20 \%$ \\
\hline Never & $54 \%$ & $61 \%$ & $84 \%$ & $72 \%$ & $92 \%$ & $73 \%$ \\
\hline
\end{tabular}


equipment, with $23 \%$ usually or always using helmets, $20 \%$ always or usually wearing slide gloves, $7 \%$ usually or always using kneepads and lights or reflectors. Over $50 \%$ of respondents never used any extra safety equipment. Views on safety equipment among focus group participants were mixed. Most participants seemed content with their current level of safety equipment use, whatever that level was, and felt that they were using their best judgment to protect themselves while they skated. However, acceptance of minor injuries as a normal part of skating was high in all groups, with nearly all participants eager to share their 'war stories'. It seems as if injuries have been somewhat normalized within skating culture; the perceived usefulness of safety equipment may be different in this context then it might appear to other groups.

From a policy standpoint, efforts towards reduce skateboard injuries might be most effective if they balanced a focused on improving pavement quality with support for the use of wrist and elbow protection and helmets and lights. Other safety measures fall into the realms of design, social, and regulatory steps, all of which would need to work together in order to achieve the safest possible skating environment.

\section{Regulatory Policy and Enforcement}

The current regulatory climate for skateboarding varies widely between municipalities across the U.S. and Canada. In a review of current skateboarding regulations in California, Fang found that $90 \%$ of cities prohibited skateboarding in specific locations, while $53 \%$ of cities had behavioral regulations such as prohibitions on reckless riding or policies requesting that skaters ride

Figure 23: Excerpt on Legality

On the transportation side, does the city want to have criminals or commuters? -Focus Group Participant with caution (Fang, 7). Of the 60 cities reviewed nearly half had both location 
and behavior regulations, over a third regulated location only, and one in ten had no regulations (ibid.) This sets the tone for the great variation of experiences, opinions, and policies currently in place and framing current discussions of skateboarding policy.

When discussing what measures could improve skating as a mode of transportation skaters from across the U.S. and Canada stressed the need for legalization of skating, and the recognition of skating as a means of travel. The ability to legally skate on either the street or the sidewalk, combined with education about current skate law amongst enforcement officials, were repeatedly cited as advantage (where they existed) and requests (where they didn't). Most discussions about regulation resulted in a suggesting that regulations for skaters be similar to regulations for cyclists, enabling effective travel, ensuring a measure of responsibility, but not restricting the mode to a few specific on-street routes.

One finding which emerged across the data was that even in places where skateboard laws are clearly articulated, their implementation is often not consistent with written policy. Much of this confusion seems to be dependent on the dynamic between skaters and enforcement officials. Restrictions placed on skaters seem from the skaters' perspective - to have more to do with the specifics of a given encounter between skaters

Figure 24: Excerpts on Policy and Compliance Treat it like a bike ... think there's education on both sides. If a city is going to take the steps to make it legal than officials and police need to take steps to educate themselves on ways that people actually use skateboards and how they get around town with them. And inevitably skaters need to become a little more responsible which might be slightly hard, but I think applying bike laws to skaters is fair. -Focus Group Participant

The biggest barrier I see to skating being accepted as a legit form of transport is the same issue bikes have- they want traffic laws to protect them, but don't want to follow traffic laws that inconvenience them. I suspect it will be difficult to get skaters to drop the outlaw status and try to fit in with civilized society; it's a bit like herding cats. -Survey Respondent 
and enforcers than with any standing policies which are in place. Interpretations of skating regulations, where they did exist, sometimes seemed to vary from one enforcer to the next. Portland skaters report being instructed by police to skate on sidewalks instead of in the street in the City's downtown core, in direct violation of the city's skating bylaws. In other cities as well existing bylaws seemed open to interpretation at the street level. Survey respondents stated a desire for consistent enforcement of existing policies, even where that regulatory structure was restrictive, as preferable to case-by-case treatment.

The theme of caution or reluctance towards regulation is the flip side of acknowledged need for skating regulation. This concern was based in the knowledge that any increase in official policy regulating skaters' behaviors could limit skaters' current freedoms (whether legal or illegal). I believe that the motivations behind these concerns had a couple of origins. First, many skaters have experienced negative social bias, and the notion of that bias having regulatory teeth raises logical concerns. Second, skaters acknowledge that there is an aspect of rebellion embedded within their subcultural identity. Maintaining that fundamental feeling of freedom is important to skaters, and several focus groups mentioned that, while the majority of skaters would likely welcome regulations which helped them skate legally for transportation they anticipated that there would always be a few skaters who choose not to abide by regulations, and in doing so diminished the opinion of skate culture as a whole in the view of those enforcing the regulations. Focus groups participants articulated an openness to increased regulation in exchange for legalization. It is possible that legitimizing skateboarders as road users via regulatory measures could ease the frustrations associated with skateboarding's often-vague status in streets. As a corollary, any regulatory measures related to skating would likely have to most success if stakeholders from the skate community were fully included in drafting 
and implementation, and discussions about self-regulation within the skate community should be initiated early in order to achieve logical and enforceable regulations and also maximize the number of skaters who would welcome regulation from the outset and act as educators within the skate community. Further policy implications for enforcement mainly focus on streamlining communication about existing bylaws which cover skateboarding in order to bring regulations and enforcement practices into synch.

\section{Land Use Policy}

One other unexpected policy request related to skate parks arose throughout the data. Skaters asked for a more dispersed approach to skateparkstyle installations. The model for providing skatepark infrastructure in many

cities consists of one or more fully developed skate parks. Skaters

described barriers of transportation access to those parks, and in the mode

use analysis many skaters indicated that they regularly drove to skate spots in order to skate. This model of providing space to skate could be called the high-infrastructure, lowdensity model - parks offer several different structures to skate, but they are located far apart from each other. Participants who had skated throughout the U.S. and Canada
Figure 25: Excerpts on Skate Park Siting It's not "we'll improve this one park and then stash you there". Throughout the city there's things here and there. And that's how trick skating is. There's little spots around town. It would be really nice to have.

-Focus Group Participant

In San Diego for 5 years every time they improved a park they'd put a little something in for skaters. If they're putting benches there's be a main picnic area or whatever and then off to the side on a little path there's be a little bench with a little sign saying "this is a skate obstacle, skate at your own risk" same as any other skate park.This is one little thing, it's for you guys. Throughout the city they'd have these little mini parks. Some of them are a handrail and a bench - a little flat bar and a bench. Little things like that.

-Focus Group Participant requested a different model of skating infrastructure. They described low- 
infrastructure, high-density skating facilities as a better fit with their travel and recreation patterns. Implemented as "skate dots" the Seattle Citywide Skatepark Plan these, installations are "integrated skatable terrain designed to blend seamlessly into small neighborhood parks ... [which] should complement or enhance adjacent landscaping, and may support other types of uses beyond skateboarding" (Parents for Skateparks, 1). Skaters described locations where these small skate facilities were installed as part of routine park renovations. This model was favored over the high infrastructure low density model by the majority of focus group participants. Land use and recreation planning initiative may want to explore more disperse skatepark type installations for skateboarders, integrated into existing public spaces.

\section{Skateboarders as Citizens}

Three main themes emerged in skaters' understanding of their role as citizens and road users. First was a desire for skating to be acknowledged as a legitimate activity, next was an investment in increasing neighborhood safety in and around skate spots, and third was an attitude of caution about new regulatory measures regarding skating. These three themes were not interlinked, instead relating to aspects of skating discussed above.

Skaters' desire for legitimacy was often expressed in the context of commute trips or other skate travel where conflicts arose over shared road use. Skaters expressed frustration that they were not viewed as equal road users. Examples of social bias against skaters also prompted this desire. In both the social sphere and in spatial politics skaters expressed a wish for some space to call home.

Skaters expressed an awareness of their role in neighborhood safety systems in a range of ways: in two focus groups discussion emerged about self- 
regulating practices which included either street or neighborhood safety. One example was the fast downhill runs in Portland's west hills which were at a point of regulatory and social conflict at the time of data collection. In the wake of resident complaints and recent policy changes local skaters described taking safety regulation upon themselves by acting as event monitors, developing collaborative relationships with the police department, and city officials, and engaging in a process of dialogue around regulatory changes on the issue.

In another example of conscious civic actions, skaters" accounts of a skater-built skate park in the Brooklyn neighborhood of Portland describe acting as 'eyes on the street' once they established the park, monitoring Figure 26: Excerpt on Skaters as Neighbors Brooklyn [skatepark] started with just just Jersey barriers. It was this empty lot where a whole bunch of bums were hanging out doing heroin and coke and whatever.

dangerous behaviors in collaboration with the police and even unofficially patrolling after dark to reduce drug use and graffiti at the site. While academic narratives of skaters often characterizes their presence in public space as disruptive, skaters viewed themselves as the safety buffer between conventional public uses and dangerous illegal uses. Skaters They went through and cleaned up all the stuff that was in the dirt and they started quick-creting in little bits and expanding and expanding to the point where we have city sanctioning, we have permits to continue to build.Skateparks can really turn around neighborhoods too. Brooklyn is a really good example. There was a lot of drugs, homeless - not necessarily just homeless but potentially dangerous homeless people living in that area. And now there's constant community surveillance and presence because of the skate park. -Focus Group Participant acknowledged that they were often viewed as a nuisance, but they tended to view themselves as performing a needed intermediary role in keeping their communities safe. Based on their own understanding of community dynamics, skaters can be valuable allies in community safety, willing to exchange their time and energy for sanctioned spaces in which to gather and skate. 


\section{Mental Health Benefits of Skating}

One of the more surprising (and most consistent) findings in the data was the extent to which skating was employed as a mechanism for mental and emotional well-being. Eighty-one

excerpts were coded for beneficial mental health during the course of analysis. Respondents described skateboarding as meditative, restorative, a form of catharsis, or a way of letting go of negative aspects of their lives. The statements varied from skater to skater, but the depth of positive personal impact from skating was consistent. This use of skating could be viewed as proactive self-care or a resource for improving mental and emotional health.

While many older respondents reported that the levels of social stigma regarding skating have decreased over the last two decades, respondents of all ages recounted conflicts with enforcement officials, city policymakers, shop owners, and other road users. The stigmatization of a practice which functions as mental health support and which is deeply woven into
Figure 27: Excerpts on Skating and Mental Health

I think it must trigger some major endorphin release for me, because my emo mood is always better when I skate somewhere.

-Survey Respondent

Everytime I step on my board, all the stress and anger is gone.

-Survey Respondent

Skateboarding is my therapy, when I'm angry I take it out on my tricks, it brings me peace. -Survey Respondent

Adrenaline, the endorphin release, exercise, the health benefits, to be able express my self, and to feel creative. I have a passion for it. Its reliable, the range of emotions experienced through skating.

-Survey Respondent

Skating is my mode of transportation, it is my therapy, my instrument, my weapon for expressing myself, my religion, my family, and my gym. There is nothing like it.

-Survey Respondent

Skateboarding puts me in to a different state of mind. The focus required to protect yourself from injury at all times allows other parts of the brain to relax. I try to enter a Zen state where my mind is totally blank and my body reacts perfectly to it's external stimulus. It feels like you are in tune with the universe for that moment.

-Survey Respondent

practitioners identities is of some concern. Categorizing an activity that has 
physical health benefits, low environmental impacts and a high degree of sustainability, combines easily with other transportation modes, and which functions as a supportive social network for young people as undesirable or problematic could be a detriment to a range of stakeholders over the long term.

Policy implications for the mental health benefits of skateboarding are two-fold. First, the legitimization of skating as a form of self-care could be useful in clinical contexts - identifying skating as an avenue for improving emotional quality of life could open new avenues for connection for therapists, schools, and other groups which work to support young adult populations. Second, the recognition that skating provides emotional and mental benefits may help to add urgency or validity to projects such as regulations for skating as transportation or the construction of skate parks.

\section{Skating as a Multi-Generational Subculture}

Several different stories emerged repeatedly in the data and supported the development of this theme. Many skaters reported first encountering skateboarding through 1980's and 1990's media representations including the Teenage Mutant Ninja Turtles, the X-Games, and the Tony Hawk skateboarding video games. Many more respondents described learning to skate or inheriting discarded boards from older friends and relatives. Skating is no longer a new sport. It has a legacy within popular culture and sports history, and it is now passed on at the local level without many geographic barriers, or electronically through online footage and publications. Suggestions from the early days of skating that new skaters be monitored by parents or attend 'skate school' programs to learn the basics of the sport may still be applicable in some situations, but are often no longer a part of the transmittal process of skill acquisition (Smith 122). The notable exception to the parental oversight noted 
above are the cases where respondents describe skating with their children. This took many forms in the data - some first learned to skate along with their children, some re-engaged in skating as a way to be active together, and some integrate it into multi-modal family travel schemes. In some of these cases skating is utilized for transportation as well as recreation.

Figure 28: Excerpts on Skating with Family I keep a few boards in the car. My son and I I frequently skate the final mile to limited parking events, like paddle board races, art shows, park concerts. Easy in easy out. -Survey Respondent

Long walks with my son in his stroller, when the path permits I'll skate behind the stroller, while pushing.

-Survey Respondent.

Skating is also now embedded in the life experience for individuals involved at various levels of civic, service, and political life. This could make for smoother relations between skate communities and policy-makers, and greater access for skate groups. As skate policies change there may be policy-makers, activists or civic leaders in decision-

Figure 29: Excerpts on Skaters in Civic Roles making roles who have first-hand knowledge of skaters' needs and wants, and whose "prior roles and identities are never fully abandoned", leaving a legacy of skate experience which can be drawn upon for later policy, research or advocacy purposes I do a lot of downtown runs [for my business]. Going to kinkos, to the revenue bureau, to board meetings with my skateboard.They'll make fun of me like "you still a teenager?" It’s like "no, multimodal!"

-Focus Group Particpant

The elected officials look at you a little strangely when you skate to work and you are a local government official.

-Survey Respondent

(Ferrell and Hamm 8).

The multi-generational aspect of skating may also be helping to shape decisions which take place within skateboarding subculture. Many participants report lessening conflicts with enforcement officials as they matured. It could be this group of adult skaters who could speak for skateboarding in the policy arena, where youthful advocates sometimes face challenges of legitimacy. 
Policy implications associated with the wide age range of current skaters include the possibility that skaters of different ages could work together, inside and outside the policy arena, so define the needs of the skating community.

\section{Skaters' Understanding of Active Transportation}

There seemed to be, amongst many skaters, an innate understanding of the idea of active transportation. In describing the advantages of skating every focus group reached consensus that a main advantage in skating was its multidimensional utility. Fitness and health, engagement with the community, convenience over short distances, and ease of transitioning to pedestrian or public transit modes were described in depth within every group and throughout the survey data. After two years of research on bicycle commuting including many meetings with cycle-focused families I can honestly state that I have never worked with a group that had such a developed understanding of the benefits of active transportation, drawn purely from their own experiences and emerging again and again in their opinions in almost complete form - usually articulated without the assistance of definitional umbrella of active transportation policy.

The skateboarders who participated it this study were remarkably adept at synthesizing the range of benefits often cited as characteristics of active transportation, as a single set of reasons for skateboarding. The advantages of fitness, convenience, interaction with outdoors or neighborhoods, and convenience for short trips were repeatedly presented together as a grouped set of reasons to ride. 
This high degree of familiarity with the aspects of active transportation has some intriguing policy implications. Many active transportation education and support strategies target families, school commutes, or individuals with a great degree place-based investment such as home owners. Collaboration between active transportation policy or research agendas and skateboarders either in college settings or within the subculture could offer relatively great pay-offs of newly identified participants in active transportation initiatives for a modest investment of policy or programmatic support. This would benefit the active transportation agenda in the shape of measurable benefits, and it would benefit skaters by having policy-makers, funders, and Figure 30: Excerpt on Active Transportation

I look at kids skating around town and I think that's awesome. It's exercise and part of creating a vibrant community. It's like, city officials are trying to figure out how to revitalize downtowns, how to create neighborhoods that are lively and full of people of all generations, embracing skateboarding on a policy level could encourage that. And maybe could encourage "here's how to safely skate in the street and here's what's expected of you" and "here's how to take part in your community". You might get some great results from that down the road.

Not only are you getting people who are more energetic and more healthy and everything, you're creating a neighborhood that's alive. I don't care if it's bikes, skateboards, roller skates, whatever. People aren't closed in boxes. They can be with each other. I guess just take an open eye to skateboarding as transportation and as something that's good for the health of a community as well.

-Focus Group Participant

other officials perceive value

legitimacy in the diverse benefits of skateboarding. 


\section{Conclusions}

\section{Future Research Needs}

It is my hope that this research will be a helpful starting point for researchers exploring further questions skateboarding as transportation. Over the course of this project further research agendas emerged. They covered social, transportation, land use, and other dynamics, including:

- How do type of skateboard, grade change, and other factors impact comfortable trip lengths for skateboarders? Findings could be applied to Safe Routes to Schools and other active transportation incentive programs.

-What part does gender play in decisions to skate for transportation? The low response rate from female skaters suggests that further research is needed here, perhaps either developing a current ethnographic snapshot of the skateboarding population with a focus on gender, or exploring the differing needs and priorities for skateboarding as a transit form between men and women.

- How are safety and ease of use for all users impacted when a new travel mode joins existing users on our right-of-ways? Solutions such as complete streets and bike boulevards are introducing designs to accommodate a wider range of users than traditional auto-centric streets, but there is still much to understand about the street use negotiations taking place between skaters and other road users.

-What types of skateboarding regulations establish the safest and most convenient access for all users? Because of variables such as grade change, paving quality, and existing regulations it is likely that this question would be dealt with most effectively on a city level. 
- Is skateboarding for transportation an exclusively urban phenomenon? While the immediate answer here is no, further research could clarify the percentages of skaters in urban, urban edge, small town, and rural environments and identify their varying need and concerns as travelers.

There are also some areas of research where information on skateboarders might increase the depth or utility of research:

- The compatibility of skateboards with multi-modal transit could help answer questions about the best ways to understand multi-modal trip-making behaviors, while controlling for the varied accommodations of bicycles in different cities' transit systems.

- The predominantly young male skating population could help researchers focus on safety choices for this demographic, including the importance of 'coolness' and the social dynamics associated with adopting and normalizing safety gear.

- The advantages and barriers documented here could be a prototype for understanding the travel behavior of the modes with tiny mode-splits which also use the street infrastructure, such as motorized wheelchairs, roller skaters, and push scooters. Many of these vehicles have small wheels which may be vulnerable to variations in paving quality at similar rates to skateboards.

Perhaps further research on skating as a mode of transportation can help broaden our understandings of street uses, our increasingly of multi-modal system, and the range of experiences and priorities of street users. 


\section{Conclusion}

This research was purposefully exploratory. With preceding literature acting as a safety net but not a foundation, the goal of this project is to simply fill in a few knowledge gaps with preliminary data. As non-motorized transportation research matures into a more complex and dynamic system the definition of what can be used as transportation seems to be getting broader. By bringing an additional mode into the non-motorized research literature I have attempted to define a place for skating within the established understanding of transportation.

Research findings from this survey and focus group suggest that skating is a viable and currently used mode in municipalities across the U.S. and Canada. While the subculture of skating and some of the needs of skaters within the transportation system are unique, the majority of values and priorities held by skaters are common across modes. Skateboarding for transportation requires a safe physical space to travel, awareness from other road users, and regulations which are both supportive and protective. They identify with their mode and are proud of their conveyances and their accomplishments just as skilled drivers or cyclists are. Skaters view their travel as enjoyable, convenient, and a logical way to move from place to place. 


\section{Bibliography}

Babey, Susan H, Theresa a Hastert, Winnie Huang, and E Richard Brown. "Sociodemographic, Family, and Environmental Factors Associated with Active Commuting to School Among US Adolescents." Journal of Public Health Policy 30 Suppl 1, no. 5 (January 2009): S203-20. http:/ /www.ncbi.nlm.nih.gov/pubmed/19190574.

Bachand-Marleau, Julie, Jacob Larsen, and Ahmed M. El-Geneidy. "MuchAnticipated Marriage of Cycling and Transit." Transportation Research Record: Journal of the Transportation Research Board 2247, no. -1 (December 1, 2011): 109-117.

http:/ / trb.metapress.com/openurl.asp?genre=article\&id=doi:10.3141/224 7-13.

Bachman, Rachel. "Utility and Thrills Put Longboarding on the Rise in Portland." Oregonian 2 June 2010.

Becky Beal. "Alternative Masculinity and Its Effects on Gender Relations in the Subculture of Skateboarding." Journal of Sport Behavior 3, no. 1996 (2010): 111.

The History of Snowboarding. The Beginning of Snowboarding: 1982. 10 Feb 2013. http://www.sbhistory.de/hist_in_the_beg.htm\#1982.

Bonham, Jennifer, and Barbara Koth. "Universities and the Cycling Culture." Transportation Research Part D: Transport and Environment 15, no. 2 (March 2010): 94-102.

http:/ /linkinghub.elsevier.com/retrieve/pii/S136192090900114X.

Borden, Ian. Skateboarding, Space and the City: Architecture and the Body. Berg Publishers/Oxford University Press, 2001.

City of Toronto Bike Plan: Shifting Gears, City of Toronto, 2001.

Colucci, Erminia. “'Focus Groups Can Be Fun': The Use of Activity-oriented Questions in Focus Group Discussions." Qualitative Health Research 17, no. 10 (December 2007): 1422-33.

http:/ /www.ncbi.nlm.nih.gov/pubmed/18000081. 
CPTED Vancouver Design Centre for CPTED. 20 Jan 2013.

http://www.designcentreforcpted.org/

Crime Prevention Through Environmental Design for Urban Village Centers San Diego Police Department. City of San Diego. 20 Jan 2013.

http://www.sandiego.gov/police/pdf/CPTEDvillagesmay2005.pdf.

Dehaas, Josh. “But It's Not a Skateboard." MacLean's, 2 Oct 2010. Print.

Dill, Jennifer, and N McNeil. "Four Types of Cyclists? Examining a Typology to Better Understand Bicycling Behavior and Potential." Transportation Research Board 92nd Annual Meeting (2013). http:// docs.trb.org/prp/135213.pdf.

Dill, Jennifer and Kim Voros. "Factors Affecting Bicycling Demand: Initial Survey Findings from the Portland, Oregon, Region." Transportation Research Record: Journal of the Transportation Research Board. No. 2031 (2007)

Dougherty, C. “Skateboarding Capital of the World." The Wall Street Journal (2009): 12-15. Print.

Fang, Kevin. "Skateboarding as a Mode of Transportation: Review of Regulations in California Cities and College Campuses." Transportation Research Board 92nd Annual Meeting 2013. http:/ / trid.trb.org/view.aspx?id=1242068.

Ferrell, Jeff, and Clinton R. Sanders. Cultural Criminology. UPNE, 1995. http:/ / books.google.com/books?id=NnQx2_586TAC\&pgis=1.

Ferrell, Jeff and Mark Hamm, eds. Ethnography at the Edge: Crime, Deviance, and Field Research. Northeastern University Press, Boston, 1998.

Garrard, Jan, Geoffrey Rose, and Sing Kai Lo. "Promoting transportation cycling for women: the role of bicycle infrastructure." Preventive medicine 46.1 (2008): $55-59$.

Glaser, Barney G., and Anselm L. Strauss. The discovery of grounded theory: Strategies for qualitative research. Aldine de Gruyter, 1967.

Haworth, Narelle, and Amy Schramm. "How Do Level of Experience, Purpose for Riding, and Preference for Facilities Affect Location of Riding?" Transportation Research Record: Journal of the Transportation Research Board 2247 (December 1, 2011): 17-23. 
http:/ / trb.metapress.com/openurl.asp?genre=article\&id=doi:10.3141/ 224 7-03.

Hunter, Jamie. "The Epidemiology of Injury in Skateboarding" Epidemiology of Injury in Adventure and Extreme Sports, Heggie, T.W. and D.J. Caine, eds. Karger, Basel (2012).

Inoue, Nobu, Ruth Baker, and Debbie Scott. "Injury Bulletin: Skateboard Injury." Queensland Injury Surveillance Unit no. 105 (2009).

Karsten, Lia, and Eva Pel. "Skateboarders Exploring Urban Public Space : Ollies, Obstacles and Conflicts." Journal of Housing and the Built Environment 15 (2001): 327-340.

Landis, B. W., Vattikuti R. Vattijuti, and Michael T. Brannick. Real-Time Human Perceptions: Toward a Bicycle Level of Service. In Transportation Research Record 1578, TRB, National Research Council, Washington, D.C., 1997, pp. 119-126.

Learn, Scott. "Hales Charts Course Amid Political Storms." Oregonian 25 Feb 2000. Print.

Lees, Loretta. "The Ambivalence of Diversity and the Politics of Urban Renaissance: The Case of Youth in Downtown Portland, Maine." International Journal of Urban and Regional Research 27, no. September (2003). http://onlinelibrary.wiley.com/doi/10.1111/1468-2427.00469/abstract.

Lefebvre, Henri. "The right to the city." Writings on cities (1996): 63-181.

Lloyd, Barbara. "Archives For Skateboard Fans, A New Way to Travel." New York Times. New York, 1992. http:/ / www.nytimes.com/1992/02/22/news/for-skateboard-fans-a-newway-to-travel.html?pagewanted $=$ print\&src $=$ pm Page.

Love Park: Saga of a Skate Landmark. On Video Magazine winter 2004. Since closed, available archived http://www.skatevideosite.com/skatevideos/onvideo-winter-2004/soundtrack Video.

Mars, Bruno. “In and Out of LOVE." 99\% Invisible 23 Jan 2013. http:/ /99percentinvisible.org/post/41291736390/episode-71-in-and-outof-love. Podcast. 
Mokhtarian, Patricia L., and Ilan Salomon. "Travel for the fun of it." Access (15) (1999): 20-31.

Mullen, Rodney. Pop an Ollie and Innovate. TEDtalks http://www.ted.com/talks/rodney_mullen_pop_an_ollie_and_innovate.h tml. Video.

Municode. $\S 427.300$. Rollerskating and Skateboarding. Minneapolis, Minnesota Code Ordinances, 2013. http:/ /library.municode.com/index.aspx?clientId=114 $90 \&$ stateId $=23 \&$ stateName $=$ minnesota\&ds $=427.300$

National Center for Transgender Equality, Transgender Terminology, 2009. http://transequality.org/Resources/NCTE_TransTerminology.pdf (Accessed April 2013).

Németh, Jeremy. "Conflict, Exclusion, Relocation: Skateboarding and Public Space." Journal of Urban Design 11, no. 3 (October 2006): 297-318. http://www.tandfonline.com/doi/abs/10.1080/13574800600888343.

Nolan, Nicholas. "The Ins and Outs of Skateboarding and Transgression in Public Space in Newcastle, Australia." Australian Geographer 34, no. 3 (November 2003): 311-327. http://www.tandfonline.com/doi/abs/10.1080/0004918032000152401.

Ostendorf, Jon, and Joel Burgess. "Skateboarders Aim to Flip Commuter Bans". USA Today, (1 April 2011:) http:/ / usatoday30.usatoday.com/news/nation/2011-01-04skateboards04_ST_N.htm

Parents for Skateparks. What is a Skate Dot? http://www.parents4sk8parks.org/pdf/SalmonBay2011.pdf

PDX Downhill. What Is PDX Downhill? https:// pdxdownhill.com/what-is-pdxdownhill/

Pomerantz, Shauna, Dawn H. Currie, and Deirdre M. Kelly. “Sk8er Girls: Skateboarders, Girlhood and Feminism in Motion." Women's Studies International Forum 27, no. 5-6 (November 2004): 547-557. http:/ / linkinghub.elsevier.com/retrieve/pii/S0277539504000536. 
Rogers, Peter, and Jon Coaffee. "Moral Panics and Urban Renaissance." City 9, no. 3 (December 2005): 321-340.

http://www.tandfonline.com/doi/abs/10.1080/13604810500392613.

Rosenberg, Dori E, James F Sallis, Terry L Conway, Kelli L Cain, and Thomas L McKenzie. "Active Transportation to School over 2 Years in Relation to Weight Status and Physical Activity." Obesity (Silver Spring, Md.) 14, no. 10 (October 2006): 1771-6. http://www.ncbi.nlm.nih.gov/pubmed/17062807.

Sabo, Donald, and Joe Panepinto. "Football ritual and the social reproduction of masculinity." Sport, men, and the gender order: Critical feminist perspectives (1990): $\quad$ 115-126.

Schieber, Richard A., Christine M. Branche-Dorsey, and George W. Ryan. "Comparison of in-line skating injuries with rollerskating and skateboarding injuries." Journal of the American Medical Association 271.23 (1994): 1856-1858.

SkateFriendlyPDX Safety Huey Ep. 1 Arlington Heights 25 Jul 2012 http:/ / www.youtube.com/watch?v=8-2mSt7qRCw Video.

Skate Further. Skate Further - About Us http://www.skatefurther.com/about-us/

Smith, R. G. "Skateboard injuries." Canadian Medical Association Journal 121.5 (1979): 510.

Steyn, Daniel. “The Body in Public Culture: Skateboarder." PostAmble 1, no. 1 (2004): 12-18.

Stevenson, Larry. Skateboard with Inclined Foot-Depressible Lever. Patent 3,565,454. 1969.

Stinson, Monique, and Chandra Bhat. "Frequency of Bicycle Commuting: Internet-Based Survey Analysis." Transportation Research Record 1878, no. 1 (January 1, 2004): 122-130.

http:/ /trb.metapress.com/openurl.asp?genre=article\&id=doi:10.3141/187 8-15.

Stratford, E, and A Harwood. "Feral Travel and the Transport Field: Some Observations on the Politics of Regulating Skating in Tasmania." Urban 
Policy and Research (2001).

http://www.tandfonline.com/doi/abs/10.1080/08111140108727863.

Stratford, Elaine. "On the Edge: A Tale of Skaters and Urban Governance." Social $\mathcal{E}$ Cultural Geography 3, no. 2 (January 2002): 193-206.

http://www.tandfonline.com/doi/abs/10.1080/14649360220133943.

Tominaga, GT, KB Schaffer, IS Dandan, and JF Kraus. "Epidemiological and Clinical Features of an Older High-risk Population of Skateboarders." Injury (2012).

http://www.sciencedirect.com/science/article/pii/S0020138312000423.

Vivoni, F. "Spots of Spatial Desire: Skateparks, Skateplazas, and Urban Politics." Journal of Sport \& Social Issues 33, no. 2 (March 23, 2009): 130-149. http://jss.sagepub.com/cgi/doi/10.1177/0193723509332580.

Williams, Stevie. "The Love Park Story" QuarterSnacks 13 Feb 2011. http:/ /quartersnacks.com/2011/02/the-love-park-story/ Web.

Woolley, Helen, and Ralph Johns. "Skateboarding : The City as a Playground." Journal of Urban Design 6, no. 2 (2001): 211-231.

Zimmer, Ben. Boston Globe "What is YOLO? Only Teenagers Know for Sure: A youthful slan craze flies under the adult radar" 26 August 2012 http:/ / www.bostonglobe.com/ideas/2012/08/25/what-yolo-onlyteenagers-know-for-sure/Idso04FecrYzLa4KOOYpXO/story.html Print. 


\section{Appendix A: Glossary of Terms}

\section{Cruising}

To skate slowly or non-aggressively, for enjoyment rather than to improve skills. Cruiser boards are modified from any type of skateboard with softer wheels which provide a gentle ride.

\section{Downhill}

A recreational form of longboarding, similar to downhill snowboarding. Skaters create long runs with minimal pushing or pumping, using gravity for momentum.

\section{Foot Breaking}

To slow a skateboard by resting one foot on the ground to create friction and decrease speed. For a demonstration see the Safety Huey video (SkateFriendlyPDX).

\section{Grinding}

To slide along the edge of a structure such as a stair, handrail, ramp, or bench, balancing on the metal trucks of the skateboard. Grinds are integral to an array of skate tricks. Over time this practice can etch grind marks or traces into some types of materials.

\section{Lines}

Skateboarders search for the best line - or route - through an environment. This can involve using various structures for stunts, or avoiding all barriers for a 
smooth ride. Skaters seek good lines across all skate environments from roadways and sidewalks to plazas or skateparks.

\section{Longboard}

Longboards are larger than the conventional boards most often associated with street skating. Longboards offer a smoother and more stable ride than conventional skateboards. Skaters often describe using longboarding for "cruising" type trips.

In general it is difficult to do street style tricks on most longboards because of their long wheelbase - some longboards are designed not to become air-born at all.

\section{Penny Boards}

Small plastic cruiser skateboards based on early models of skateboards. These boards have increased in popularity in recent years and are available cheaply.

\section{Pushing and Pumping}

Skaters typically generate momentum to move their skateboards by standing on the board with one foot while pushing with the other.

Skaters use pumping as an alternative to pushing as a way to create momentum. The motion of short side to side motions with the back of the board increases momentum on the same principle used by ice skaters skating backwards. Some long distance skate events emphasize pumping.

\section{Shutting Down}

Stopping quickly, usually with a slide (see slide). 


\section{Skate Deterrents / Skate Stops}

Hardware attached to ledges, benches, architectural features, or infrastructure to disrupt skateboard grinds and slides.

\section{Skate Deck}

The horizontal surface a skate stands on while skating. Often made of wood, sometimes of plastic. The top side of skate decks are typically textured for optimal grip and the underside are often used as an aesthetic design space.

\section{Skatepark}

For the purposes of this research a skatepark is defined as a purpose-built structure in private or public space where skaters gather for recreational skating. Skateparks can be private (constructed in a back yard), public (land set aside by the city as skate recreation space, often managed by the recreation department), or entrepreneurial (indoor skateparks for instruction or ramps built for extremegames competitions).

\section{Skateboard / Popsicle Stick Board}

Term encompassing all boards from super-small boards, to the street skating boards typically used for tricks, to longboards. The most widely used type of skateboard, medium sized with curved ends for aerial tricks, is referred to either as a skateboard or a popsicle stick.

\section{Slide / Powerslide}

A maneuver used both as the foundation for tricks and for breaking or slowing the skateboard. The body of the board (the nose, middle, or tail) is slid along the ground or along an object, so that the board moves without relying on rotation 
from the wheels. To break, the back end of the skateboard is brought out to the side so that the wheels rub at right angle to their direction of motion rather than rotating, thereby creating friction. Slides can be used for breaking, slowing, or controlling direction changes. Sometimes skaters wearing protective gloves stabilize slides by skimming a hand on the pavement. This can assist with stability and direction. For a demonstration see the Safety Huey video (SkateFriendlyPDX).

\section{Street Skating}

Street skating is the practice of using elements found in the public domain as the bases for tricks. These elements can include street furniture such as benches, as well as stairs, handrails, loading docks, or curbs.

\section{Thermo-plastic street markings}

Crosswalk, lane marking, and other road surface markings created with plastic and reflective additives instead of paint. Thermo-plastic tends to be slightly raised, slick, and hard-wearing.

\section{Traces / Grind Marks}

Marks, scratches, or wear left on the infrastructure or architecture as a result of grinds or other stunts. Referred to by skaters as grind marks, and by urban theorists as trace markings (Vivoni).

\section{Transition Skating}

Transitional or tranny skating - a style which uses curved or undulating structures as the base for skating lines or performing stunts. Many modern skate 
parks including the park beneath Portland's Burnside Bridge are designed to skate tranny.

\section{Trucks}

The metal hardware connecting a skate deck to the wheels. Trucks are not solid but instead rotate slightly, allowing skaters to change the angle of their board for steering or tricks.

\section{Truncated Domes}

Plastic mats with a raised half-dome texture installed at curb-cuts to assist those with visual disabilities. Truncated domes are used in some cities as ADAcompliant pedestrian infrastructure design.

\section{Vertical Skating}

Vertical or vert skating uses a half-pipe or other type of ramp to launch into the air and perform aerial tricks. The same structures can in some cases be used for vert and tranny styles. 


\section{Appendix B: Key Stakeholders Contacted for Survey Recruitment}

\begin{tabular}{|c|c|c|}
\hline Group & Type & Location \\
\hline Active Right of Way & Interest Group & Portland, OR / online \\
\hline Austin Skateboarding Club & Interest Group & Austin, TX \\
\hline Bike Portland & Publication/News/Advocacy & Portland \\
\hline Boards for Bros & Non-profit & Tampa, FL / online \\
\hline Boston Skateboarder & Interest group & Boston, MA \\
\hline Brooklyn Street Skate Spot & Skate Park/Instruction & Brooklyn, NY \\
\hline Cardinal Skate Company & Retail & Toronto, ON \\
\hline $\begin{array}{l}\text { Chief Ladiga Silver Comet Sk8 } \\
\text { Challenge }\end{array}$ & Event & Georgia/Alabama \\
\hline $\begin{array}{l}\text { Colorado Coalition for Public } \\
\text { Skate Parks }\end{array}$ & Non-profit & Denver, $\mathrm{CO}$ \\
\hline Commonwealth Skate Park & Skate Park/Instruction & Portland \\
\hline Concrete Skateboarding & Publication & Richmond, BC / online \\
\hline Copenhagenize & $\begin{array}{l}\text { Policy/Design/Advocacy } \\
\text { Publication }\end{array}$ & Denmark \\
\hline King Shit Magazine & Publication & Online \\
\hline $\begin{array}{l}\text { Launch Community Through } \\
\text { Skateboarding }\end{array}$ & Non-profit & Fort Collins, $\mathrm{CO}$ \\
\hline Maine Skateboarding & Interest Group & Maine \\
\hline $\begin{array}{l}\text { Oregon Transportation Research } \\
\text { and Education Consortium }\end{array}$ & Policy/Research Organization & Oregon \\
\hline PDX Downhill & Interest group & Portland \\
\hline Pretty Tough Productions & Publication - women in sports & Online \\
\hline SBC Skateboard & Publication & Toronto, ON / online \\
\hline Sector 9 Skateboards & Retail & San Diego, CA \\
\hline SF Skateboarding Association & Skate Park/Interest Group & San Francisco, CA \\
\hline Skate Brooklyn Skate Shop & Retail & Brooklyn, NY \\
\hline
\end{tabular}




$\begin{array}{lll}\text { Skate Further } & \text { Interest Group } & \text { Online } \\ \text { Skate Like A Girl } & \text { Interest Group/Instruction } & \text { WA / OR / CA } \\ \text { Skate Slate } & \text { Publication } & \text { Online } \\ \text { Skateboarder Magazine } & \text { Publication } & \text { Online } \\ \text { Skatepark of Tampa } & \text { Interest group } & \text { Tampa, FL } \\ \text { Skaters for Public Skate Parks } & \text { Interest } & \text { Portland } \\ \text { So Hip It Hurts } & \text { Retail } & \text { Toronto, ON } \\ \text { Social Skate Parks } & \text { Skate Park/Interest Group } & \text { California / online } \\ \text { Thrasher Magazine } & \text { Publication } & \text { San Francisco, CA } \\ \text { Vancouver Skateboard Coalition } & \text { Interest group } & \text { Vancouver B.C. } \\ \text { Whistler Longboard Festival } & \text { Event } & \text { Whistler B.C. } \\ \text { Winnipeg Skateboarding } & \text { Interest Group } & \text { Winnipeg, MB }\end{array}$




\section{Appendix C: Qualitative Code Book}

\section{Survey Codes}

Positives
Fun/Enjoyment
Engaging with Surroundings
Speed/Convenience
Mental Health/Meditative
Creativity/Art
Financial
Freedom
Enviornmental
Fitness/Exercise
Carrying/Security

\section{Negatives}

Assumptions - Social Bias

Assumptions - Safety

Weather

Paving Quality

Conflict with Traffic

Danger

Sweat

\section{As Transportation \\ Travel Characteristics \\ Compared to Other Modes \\ Travel to School/Work \\ Longboards}

Other

Gender

As Sport

As a Kid

Adult Skate Generation

Compared to Other Sports

\section{Multi-Modal \\ With Bus \\ With Train \\ With Car \\ Other Practices}

\section{Policy}

Subculture

Enforcement/Police

Many Reasons to Ride

\author{
Focus Group Codes \\ Subtypes of skating \\ Route choice / criteria / speed \\ Danger/pain philosophies \\ Policy recommendations \\ Legalization \\ Cars and body language \\ Homelessness / drugs \\ Skate to the (destinations) \\ Wipe out on (reasons for crashes) \\ Control \\ Safety \\ Pedestrians \\ Being in the moment \\ Flirtation \\ Regulating ninjas (freedom+enforcement)
}




\section{Appendix D: Text of Human Subjects Approval}

\section{Portland State University HSRRC Memorandum}

To: Jennifer Dill/Tessa Walker

From: Todd Bodner, Chair, HSRRC 2013

Date: January 9, 2013

Re: Your HSRRC application titled, "Skateboarding for Transportation: An Exploratory Study" (HSRRC Proposal \#122405)

In accordance with your request, th e Human Subjects Research Review Committee has reviewed your proposal for compliance with DHHS policies and regulations covering the protection of hum an subjects. T he comm ittee is satisfied that your provisions for protecting the rights and welfare of all subjects participating in the research are adequate, and your project is approved.

Please note the following requirements:

Please correct the HSRRC address on consen $t \mathrm{f}$ orms to the Market Center Building address.

Changes to Protocol: Any changes in the proposed study, whether to procedures, survey instruments, consent forms or cover letters, must be outline $d$ and submitted to the Chair of the HSRRC i mmediately. The proposed cha nges cannot be i mplemented before they have been reviewed and approved by the Committee.

Continuing Review: This approval will expire January 9, 2014, one year from the approval date, . It is the investigator's responsibility to ensure that a Continuing Review Report ( available in R SP) of the status of th e project is subm itted to th e HSRRC approximately two months before the expiration date, and that approval of the study is kept current.

Adverse Reactions: If any adverse reactions occur as a result of this study, you are required to notify the Chair of the HSRRC immediately. If the problem is serious, approval may be withdrawn pending an investigation by the Committee. 
Completion of Study: Please notify the Chair of the Human Subjects Research Review Committee (campus mail code RSP) as soon as your research has been completed. Study records, including proto cols and sig ned consent forms for each particip ant, must be kept by the investigator in a secure location for three years following completion of the study.

If you have questions or concer ns, please contact the HSRRC at $\underline{\text { hsrrc@pdx.edu or }}$ (503)725-2243.

cc: Brenda Fugate 


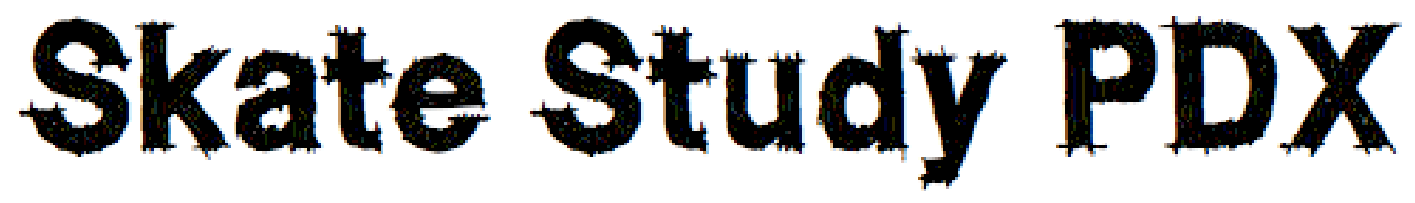

If you skate to get to work, the bus stop, or the grocery store, you're invited to join a paid focus group or take a survey to share a little bit about why and where you skate. The purpose of the research is to help urban planners and cities understand more about skateboarding as a useful mode of transportation.

You can help us if you are age 18 or older and you've used skating as a way to get around any time in the last five years. Your responses will be confidential and used for research purposes only.

To join a focus gorup or take a survey go to:

\section{www.skatestudypdx.wordpress.com}

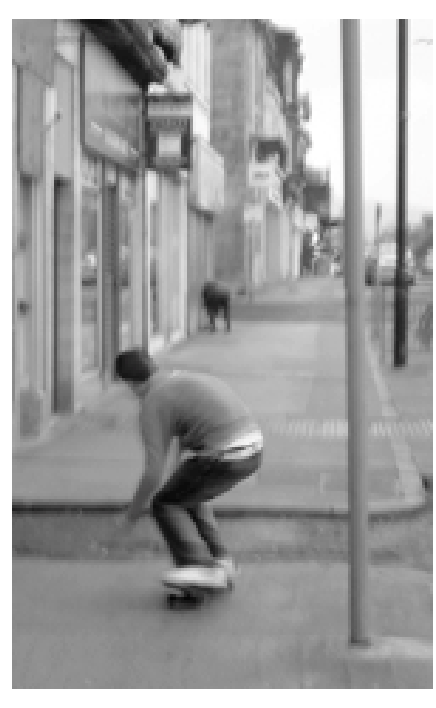

Some background: This project is thesis research being conducted by Tessa Walker, a PSU urban studies masters student. She's doing this study because skating is a fun, cheap, sustainable way to get around but there isn't much awareness of skating as a transportation option among transportation planners and other people who study how we travel around every day. 


\section{Appendix F: Focus Group Interview Guide}

Each focus group will be made up of the following three sections:

\section{Logistics}

- Consent forms

- Payment

- Demographics and travel survey (age, race, employment status, etc.)

General focus group introduction, covering:

- Roles

- Ground rules

- Taping

- Confidentiality

- Introductions (names, how they got here today)

\section{Interview Guide}

90 minute focus group, 80 minutes of scheduled questions

1. [10 min] So let's start with how you started skateboarding. It would be great if you could share how you first become involved in skating. I'm interested in hearing the range of stories you have about how you first got interested in it, where you started skating, how old you are when you started, just the different examples you have of starting out.

Probes:

-What about the types of skating you were doing - streets? home-built ramps? skate parks? public parks or plazas? longboards? 
2. [10 min] Now that we've heard a little about how you started out let's talk about your skating now. Do you primarily skate to get around town? Do you still practice stunts or skate in [locations from Q1]

3a. [15 min] Ok. I'm going to pass index cards around. I want you to think about skateboarding compared to the other forms of transportation you use - if you drive or bike or take the bus or walk a lot. Out of all of your transportation options, note down a couple of reasons why on any given trip or day you might decide to get around on your skateboard. [hand out cards, give time for writing] Now let's share some of the reasons you sometimes decide to skate.

Probes:

- If not raised by participants ask about enjoyment, convenience, exercise.

- multi-modal transportation - skateboards on the bus/MAX?

- Are there times they don't skate? Rain, grocery shopping, work commute?

3b. [15 min] What about some of the pros and cons of how you skate now? I'm hearing that skating is [fun/convenient/other info from Q3] when you use it to get around. As a way of traveling around town what are some of the up sides and down sides?

Probes:

- Prompt for positive/negative if one gets ignored

- Any problems with visibility, accidents, police

4. [20] Ok, now we're going to do another exercise. Take five minutes or so and highlight some of your favorite skating streets. You can work separately - I 
know might not travel in the same parts of town. If you highlight the same streets that's ok too. [

****Ok, now take a look at the streets you choose and describe why you tend to skate there. What makes those streets better than some of the other streets near by? Maybe a good way to think about this is to describe this street compared to another near by street you might use to get to the same destination that's not quite as great to skate on - what does this street have more of or less of? Why do you prefer skating on the streets on this route you just outlined? Just let us know as many reasons as you can figure out why those are really good skating streets.

Probes:

- Level of traffic

- good skating surface either on the street or the sidewalk

- do hills matter

- do constructed facilities matter - bike lanes, crossing signals

- Are there any really bad skating streets that you end up having to use? Why are they bad?

5. [10 min] Ok, we're at our final question. So, there's a whole range of people whose job it is to make our streets work well - the Department of transportation and the Planning Bureau do design stuff, the police monitor for traffic violations, TriMet provides public transportation. Let's say all those folks were putting together a list of things they could do to make it easier to travel by skateboard. I'd like to hear recommendations from each of you. As the experts at using this form of transportation, what two or three things do you think would make the biggest difference to make skating more fun, more safe, generally easier to use as a way to get around town? 
Appendix G: Online Survey Questionnairre

(see following page) 
Intro

Informed Consent:

You are imited to participate in a research study conducted by Tessa Walker, a Masters student at Portland State University's College of Urban and Public Affairs. The purpose of this research is to learn more about people who skateboard for transportation. If you decide to participate, you will be asked about why and where you skateboard, your opinions on skateboarding as a way to get around, some questions about laws or ordinances that regulate skateboarding where you live, and some demographics questions. The survey should take between 15 and 30 minutes to complete. You may not receive any direct benefit from taking part in this study, but the study may help to increase knowledge which may help others in the future. At the end of the survey you will have the option to enter a drawing for a \$10 gitt card to iTunes, Amazon, or Powells Books as a thank you to our study participants.

Any information that is obtained in connection with this study and that can be linked to you will be kept confidential. That means that your name, email address, and neighborhood will not be used in any papers or publications that result from this study. A code will be used to identify you on all study materials. No information about you will be shared with Portland State University or any other organization or state agency.

Your participation is voluntary. You do not have to take part in this study, and it will not affect your relationship with any state agency including Portland State University. You may also withdraw from this study at any time, or choose to leave any question in the survey blank at your discretion. If you have concems or problems about your participation in this study or your rights as a research subject, please contact the Human Subjects Research Review Committee, Office of Research and Sponsored Projects, Market Center Building, 1600 SW 4th Avenue Suite 620. Portland State University. 503-725-4288 or toll-free at 1-877-480-4400. If you have questions about the study itself, contact Tessa Walker, College of Urban Studies and Planning, Portland State University. Portland, OR, 97207. or tcwalker@pdx.edu. You can also contact Tessa's thesis advisor with any questions or concerns. Dr. Jennifer Dill, College of Urban Studies and Planning. Portland State University, 503-725-4045, jdill@pdx.edu.

Clicking the 》> button below indicates that you have read and understand the above information and agree to take part in this study. and that you are 18 years of age or older. Please understand that you may withdraw your consent at any time without penalty, and that, by clicking. you are not waining any legal claims, rights or remedies. The researcher can provide you with a copy of this form for your own records at your request.

\section{First block}

How old were you when you first started skateboarding?

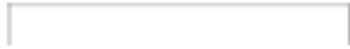

Around what age did you start:

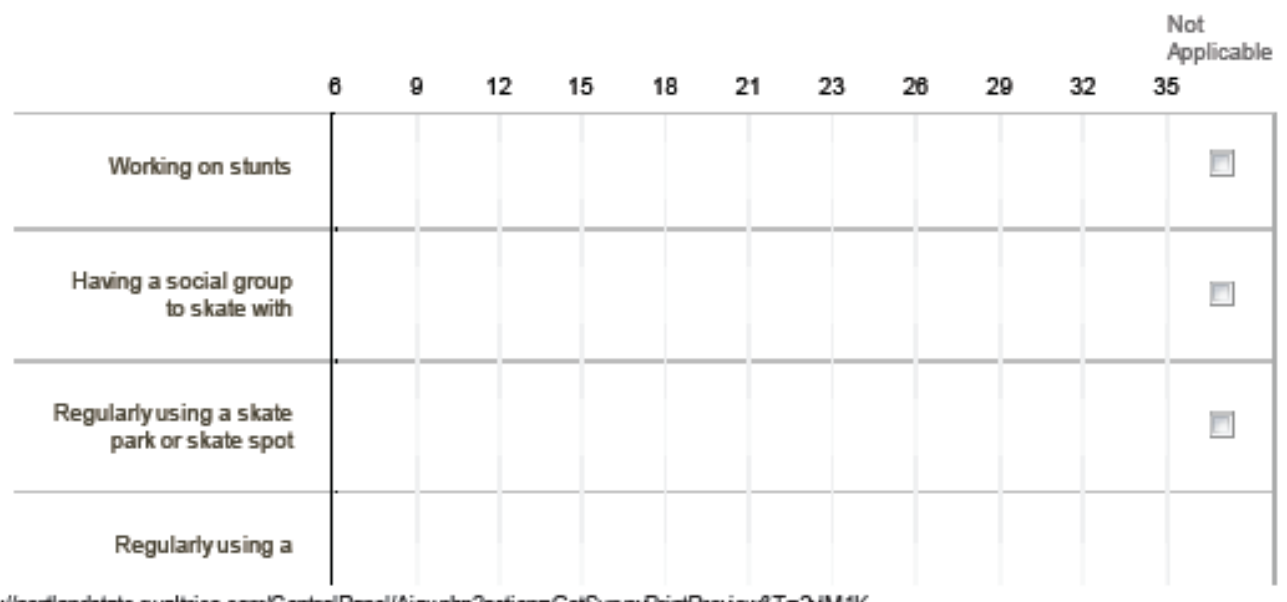

https://portlandstate.qualtrics.com/ControlPanel/Ajaxphp?action=GetSurveyPrintPreview\&.T=2yM 1K 
8/19/13

Qualtrics Survey Sothere

skateboard to get around

Around what age did you stop:

\begin{tabular}{|c|c|c|c|c|c|c|c|c|c|c|c|}
\hline & 6 & 9 & 12 & 15 & 18 & 21 & 23 & 26 & 29 & 32 & $\begin{array}{l}\text { Not } \\
\text { Applicable } \\
\mathbf{3 5}\end{array}$ \\
\hline Working on stunts & & & & & & & & & & & 回 \\
\hline $\begin{array}{l}\text { Having a social group } \\
\text { to skate with }\end{array}$ & & & & & & & & & & & 口 \\
\hline $\begin{array}{l}\text { Regularly using a skate } \\
\text { park or skate spot }\end{array}$ & & & & & & & & & & & $\square$ \\
\hline $\begin{array}{l}\text { Regularly using a skate } \\
\text { board to get around }\end{array}$ & & & & & & & & & & & $\square$ \\
\hline
\end{tabular}

How did you first become interested in skating?

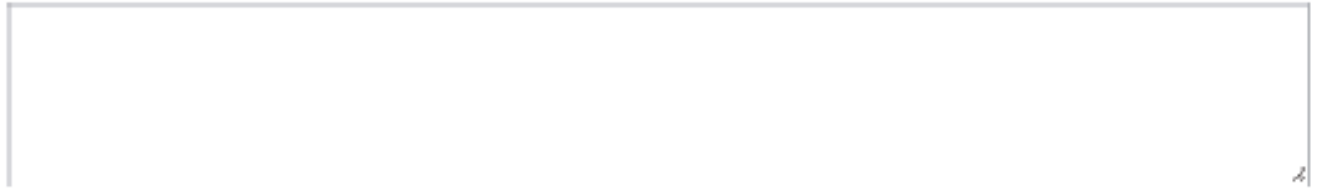

Why do you skate now (or within the past five years)?

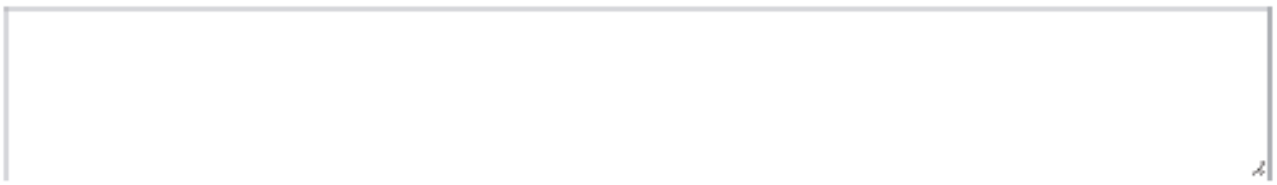

Who do you usually skate with (check all that apply)?
Dikate alone
마th friends / housemates
D with siblings / friends
D with mykids / partner
D other (please describe)

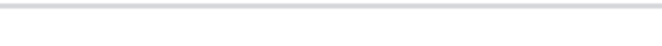

In all the trips you make town (not just skating) how often do you get around by: https:/portlandstate.qualtrics.com/ControlPanel/Ajaxphp?action=GetSurveyPrintPreview\&T=2yM 1K 


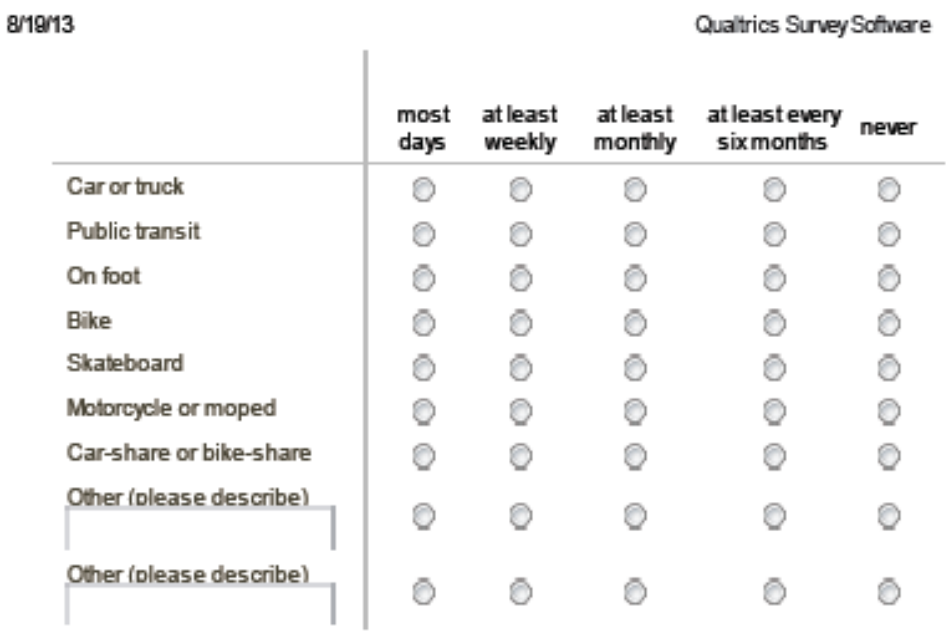

In thinking about skateboarding to get around, how would you prioritize your reasons for skating? (sort options using the up and down arrows)

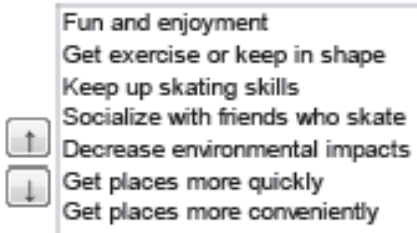

What types of skateboards do you use to travel around town?

\begin{tabular}{l|ccc}
\hline & usually sometimes & never \\
\hline Skateboard & 0 & 0 & 0 \\
Longboard & 0 & 0 & 0 \\
Other (olease describe) & 0 & 0 & 0
\end{tabular}

Choose some street features that feel like barriers and advantages when you're skating - things that help you enjoy a skate route or make you choose a different one.

\begin{tabular}{|c|c|c|c|}
\hline & advantage & barrier & $\begin{array}{l}\text { doesn't } \\
\text { matter }\end{array}$ \\
\hline Uphill slopes - gentle & 0 & 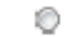 & 0 \\
\hline Uphill slopes - steep & 0 & D & $D$ \\
\hline Downhill slopes - gentle & 0 & & 0 \\
\hline Downhill slopes - steep & 0 & 0 & 0 \\
\hline Sidewalks - smooth & 0 & 0 & 0 \\
\hline Sidewalks - rough & $D$ & 0 & 0 \\
\hline Streets - smooth & 0 & 0 & 0 \\
\hline
\end{tabular}

https://portlandstate.qualtrics.comControlPanel/Ajaxphp?action=GetSunveyPrintPreview\& $\mathrm{T}=2 \mathrm{ylM} 1 \mathrm{~K}$ 
8/19/13 Quattrics Survey Sottware

\begin{tabular}{|c|c|c|}
\hline Streets - rough & $D$ & \\
\hline Car traffic - light & 0 & \\
\hline Car traffic - moderate or heavy & 0 & \\
\hline Other skateboarders & 0 & \\
\hline Bikke riders & $\theta$ & \\
\hline Bike lanes & $D$ & \\
\hline $\begin{array}{l}\text { Curb ramps between streets and } \\
\text { sidewalks }\end{array}$ & $\theta$ & \\
\hline Other (please describe) & $n$ & \\
\hline Other (olease describe) & 0 & \\
\hline Other (please describe) & y & \\
\hline
\end{tabular}

Where you live, what seasons are good for skating (choose all that apply)?
$\square$ spring
$\square$ summer
$\square$ fall
winter

When you're skating to get around, where do you usually like to skate?
On the street
On the sidewalk
D Streets and sidewalks equally
Other (please describe)

Second Block - travel diaries and trip chaining

Please give examples of some trips you typically take by skateboard. There is space here for four example trips.

For your start points and destinations enter intersections like "East 31st \& Main St" or places like "Benton Community College" or "Safeway on 12th".

(Don't worry about what town you'e in - youll be asked to enter your zip code later.)

Trip 1

Start point

What is usuallythe purpose of this trip (for example work, groceries, enrands)

About how long does a one-waytrip to this destination take by skateboard?

When you leave this destination do you usually go home, go to another destination, or get on another form of transportation (like a bus or car)?

https://portlandstatequaltrics.com/ControlPanel/Ajaxphp?action=GetSurveyPrintPreview\& T=2yM $1 \mathrm{~K}$ 
Trip 2

\section{Start point}

Destination

What is usuallythe purpose of this trip (for example work, groceries, errands)

About how long does a one-way trip to this destination take byskateboard?

When you leave this destination do you usually go home, go to another destination, or get on another form of transportation (like a bus or car)?

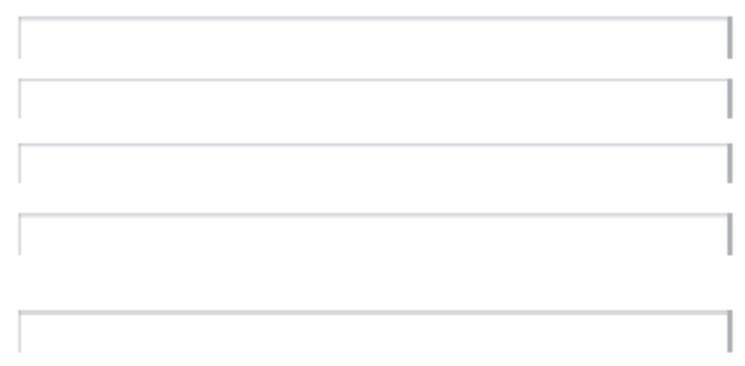

Trip 3

Start point

Destination

What is usuallythe purpose of this trip (for example work, groceries, errands)

About how long does a one-way trip to this destination take by skateboard?

When you leave this destination do you usuallygo home, go to another destination, or get on another form of trans portation (like a bus or car)?

Trip 4

Start point

Destination

What is usuallythe purpose of this trip (for example work, groceries, errands) About how long does a one-way trip to this destination take by skateboard?

When you leave this destination do you usuallygo home, go to another destination, or get on another form of transportation (like a bus or car)?

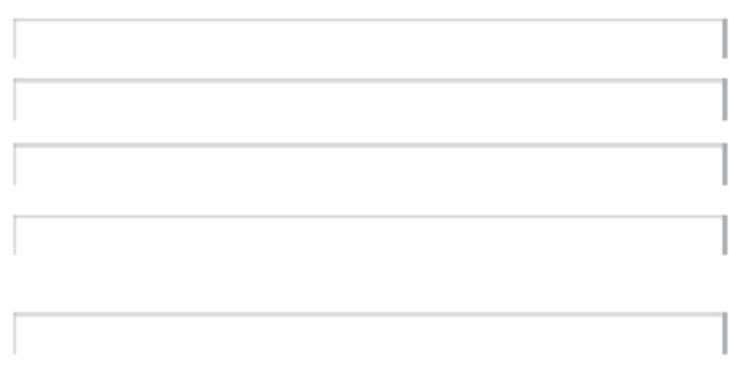

How often do you skateboard for just part of a trip (for example, skating to the bus stop and then catching the bus to work, or taking your skateboard with you when you drive to another part of town)?

$+$

Describe how you typically combine skating with other forms of transportation for getting around?

https:Ilportlandstate.qualtrics.com/ControlPanel/Ajaxphp?action=GetSurveyPrintPreview\&T $=2 y \mathrm{M} 1 \mathrm{~K}$ 


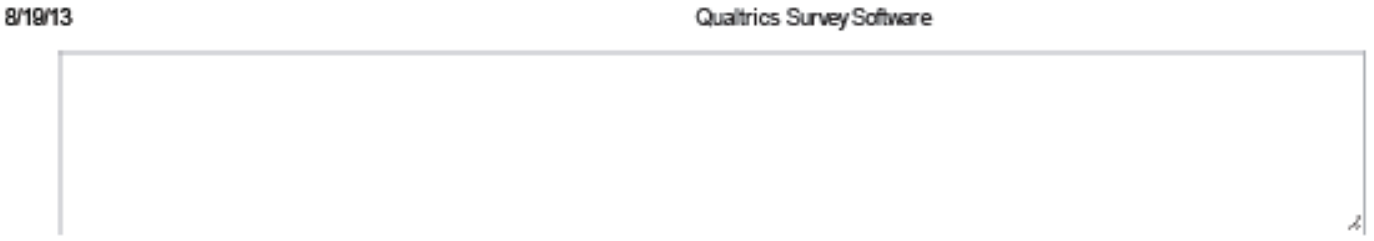

In your opinion, what are some of the advantages of skateboarding to get around?

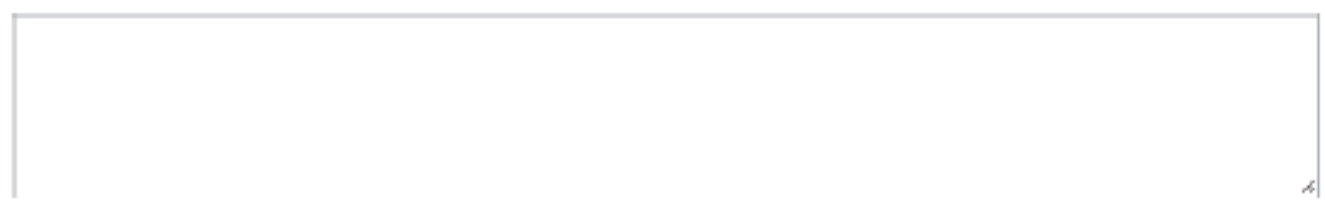

In your opinion, what are some of the disadvantages of skateboarding to get around?

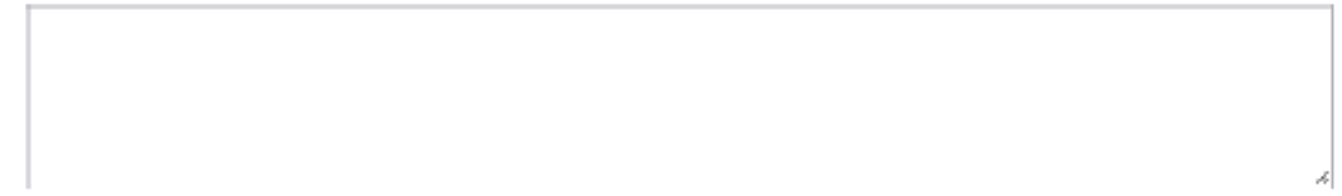

Third section - legal

What safety equipment do you use when you skate for transportation?

\begin{tabular}{|c|c|c|c|c|}
\hline & Never & Somefimes & Usually & Always \\
\hline Helmet & 0 & 0 & 0 & 0 \\
\hline Slide gloves & 0 & 8 & 0 & 8 \\
\hline Elbow pads & 0 & 0 & 0 & 0 \\
\hline Knee pads & 0 & 0 & 0 & 8 \\
\hline Wrist guards & 0 & 8 & 0 & 0 \\
\hline Lights or reflectors & 0 & 0 & 0 & 8 \\
\hline Other (please describe) & 0 & 0 & 0 & $\theta$ \\
\hline Other (olease describe) & 0 & 0 & $D$ & 0 \\
\hline
\end{tabular}

Are there laws, ordinances, or policies where you live that regulate where you can or can't skate?
Q Yes
Notsure
1 No

If there are, how are those laws generally enforced? (choose all that apply)

D Street signs

https://portlandstate. qualtrics.comControlPanel/Ajaxphp?action=GetSurveyPrintPreview\& $T=2 y M 1 \mathrm{~K}$ 
Warnings - from police or other groups

Tickets - from police or other groups

Arrests - from tickets or other groups

Laws are not enforced.

Other (please describe)

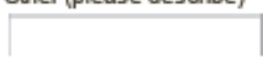

As far as you know, what local laws are there in your community about skating on streets and roads? Please describe these laws as best you can (for example, is skating on roads banned but sidewalks are allowed?)

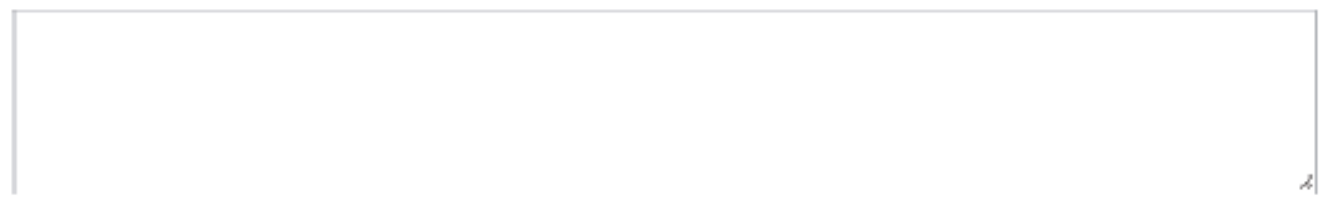

Where do you go for information about skateboarding laws where you live? (choose all that apply)
$\square$ Word of mouth / events / friends
Skate websites
Facebook/twitter / social media
Posters / zines / flyers
Print media articles
Municipal website laws and ordinances
Don't know / none
Other (please describe)

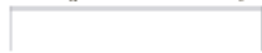

How are skateboarders typically treated by local police or other groups that enforce skate laws where you live?

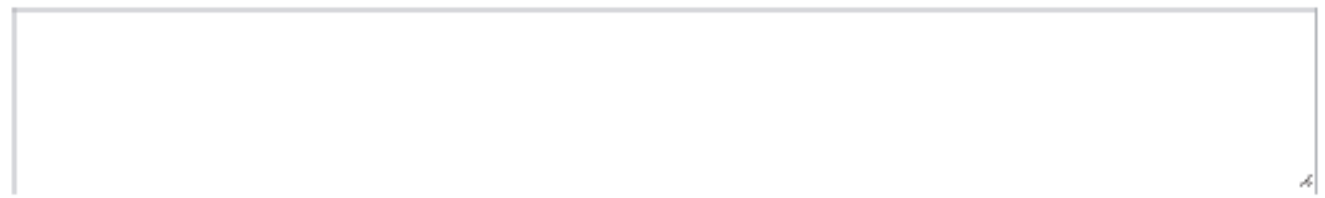

Are skateboarding groups involved in local politics where you live?
Yes
No
Don't know

Why are these skate groups involved in politics?

Lobbying / planning for skate parks

$\square$ Changes to existing laws

口

https:/portlandstate.qualtrics.comControlPanel/Ajaxphp?action=GetSurveyPrintPreview\& $\mathrm{T}=2 \mathrm{yM}$ 1K 
Changes to treatment of skaters

Other (please describe)

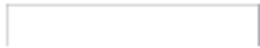

\section{Demographics}

What is your home zip code or postal code?

What is the intersection closest to your home?

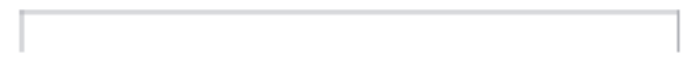

What year were you born?

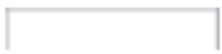

What is your gender?

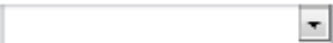

What race or ethnicity best describes you? (choose all that apply)

D Caucasian

D African American or Black

$\square$ Hispanic

$\square$ Latino

DAsian

Indian subcontinant

D Arab or Middle Eastern

D Pacific Islander or Native Hawaiian

D. American Indian or Canadian First Nations

Other (please describe)

Pror

What is your employment status? (choose all that apply)

D. Employed full-time

DEmployed part-time

DStudent full-time

[Dtudent part-time

$\square$ Currently working without pay (intern, volunteer, at-home parent, developing an art show, album, etc.) 四

https:Illportlandstate. qualtrics.com/Control Panel/Ajaxphp?action=GetSurveyPrintPreview\&.T=2yM 1K 
- Not employed

What is the highest level of education you have completed?
$\square$ Some high school
High school or GED
$\square$ vocational program or associate's degree
$\square$ Some college or university
Dachelor's degree
$\square$ Masters, PhD or professional degree

What is your current living situation? Do you
Dive alone
$\square$ Live with housemates
Live with parents or extended family
Dive with a partner and/or children
$\square$ Live in campus housing at school
Other (please describe)

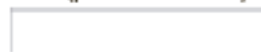

\section{Do you rent or own your home?}
Dent
Own
D Other/not applicable

Which of the following best describes your household's current finances?
Doneyis fight
I lusually do ok for money
Mbney is no problem
Q Prefer not to say

When you were a young teenager, which of the following best described your household's finances?
Moneywas tight
We usuallydid ok for money
Moneywas no problem
5 Prefer not to say

That's all the questions. Is there anything else you feel is important to share about skateboarding as a way to get around?

hthp://portlandstate.qualtrics.com/ControlPanel/Ajaxphp?action=GetSurveyPrintPreview\&T=2yM 1K 


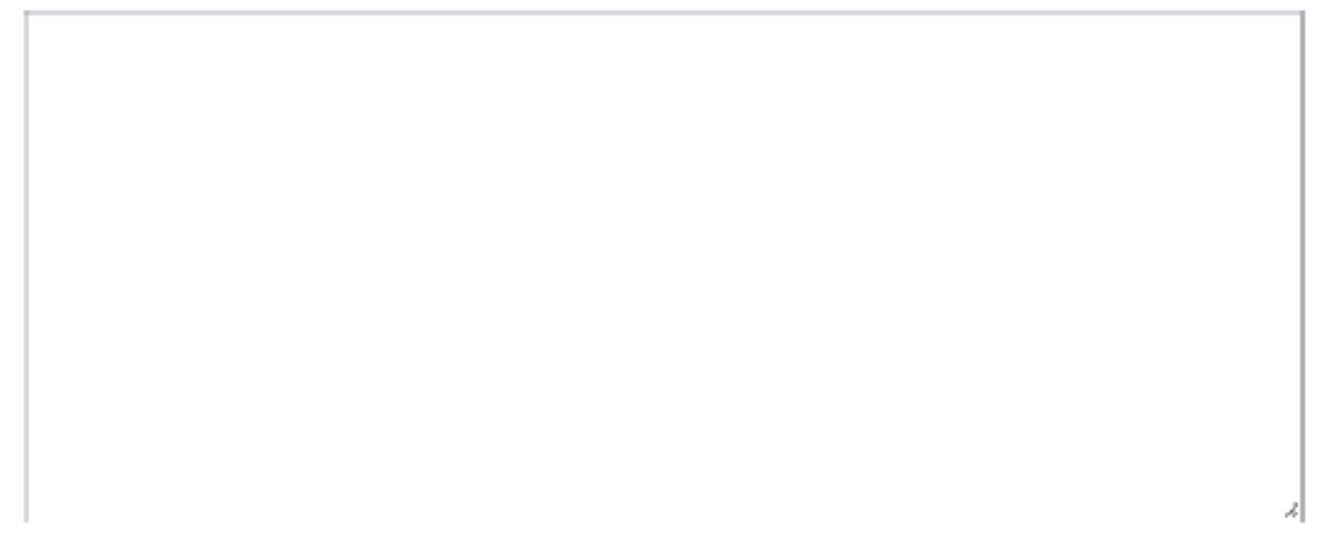

If you'd like to enter a drawing for a $\$ 10$ gift card as a thank you for taking this survey. please enter your email address.

Three winners will be randomly selected, each winner will have the choice of a gitt card to Amazon, iTunes, or Powells Books. Drawing will take place by April of 2013.

Thank you for sharing your experience. Click the $\gg$ button one more time to end the survey.

https://portlandstate.qualtrics.com/ControlPanel/Ajaxphp?action=GetSunveyPrintPreview\& $\mathrm{T}=2 \mathrm{yM} 1 \mathrm{~K}$ 